\title{
HIV/AIDS vulnerabilities, discrimination, and service accessibility among Nigeria's youth
}

Population Council

Follow this and additional works at: https://knowledgecommons.popcouncil.org/departments_sbsr-hiv

Part of the Demography, Population, and Ecology Commons, Family, Life Course, and Society Commons, International Public Health Commons, and the Maternal and Child Health Commons How does access to this work benefit you? Let us know!

\section{Recommended Citation}

Population Council. 2014. "HIV/AIDS vulnerabilities, discrimination, and service accessibility among Nigeria's youth." Abuja: Population Council. 


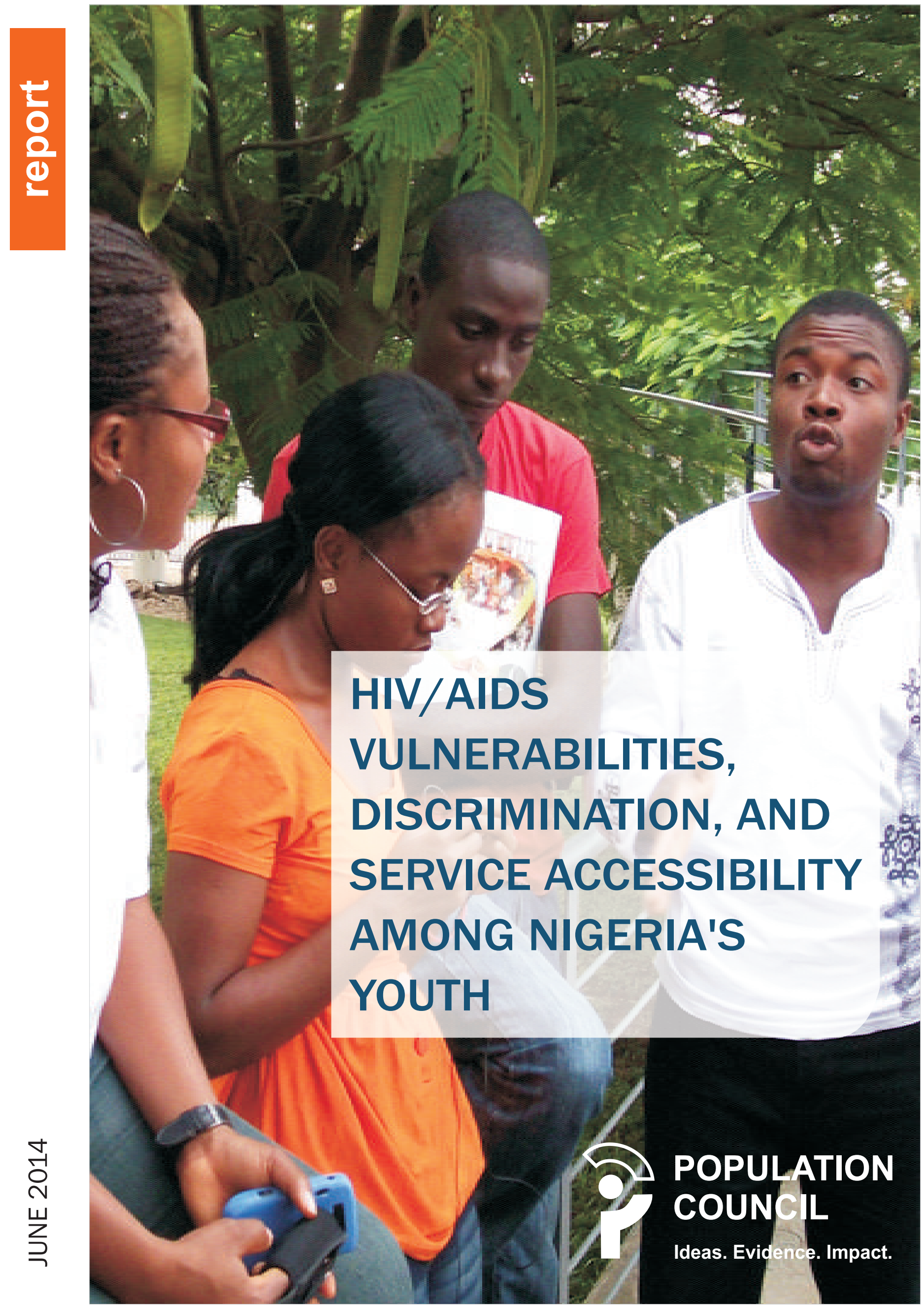




\title{
POPULATION
}

- counclL

\author{
Ideas. Evidence. Impact.
}

The Population Council confronts critical health and development issues-from stopping the spread of HIV to improving reproductive health and ensuring that young people lead full and productive lives. Through biomedical, social science, and public health research in 50 countries, we work with our partners to deliver solutions that lead to more effective policies, programs, and technologies that improve lives around the world.

Established in 1952 and headquartered in New York, the Council is a nongovernmental, nonprofit organization governed by an international board of trustees.

Population Council

No. 16 Mafemi Crescent

Abuja

Nigeria

Tel: +234 $98706071 ;+23498706057 ;+2348067787750$

email: info.nigeria@popcouncil.org

popcouncil.org

Suggested citation: Population Council. 2014. “HIV/AIDS Vulnerabilities, Discrimination and Service Accessibility of Nigeria's Youth."Abuja, Nigeria.

Cover Photo by Nigerian Youth Climate Coalition (NYCC)

(C) 2014 The Population Council, Inc. 


\section{Acknowledgements}

This publication is based on research funded by the Ford Foundation and conducted by the Population Council. Our team of investigators was instrumental in the research process. Most especially, we thank the key informants and youth who graciously gave their time and shared insights and intimate details of their experiences as participants in the research. This study is dedicated to them and to the goal of HIV prevention and impact mitigation among youth in Nigeria and beyond. 


\section{Table of Contents}

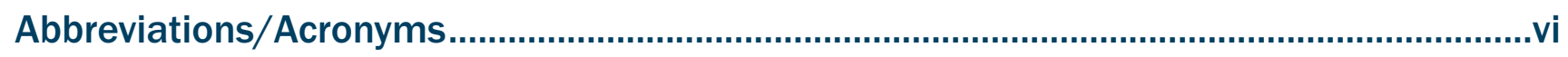

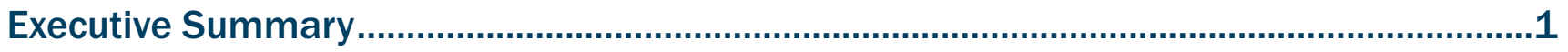

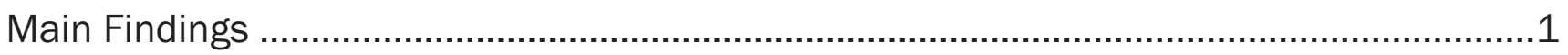

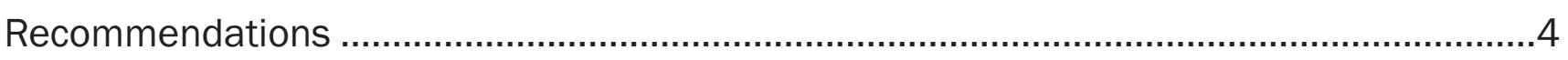

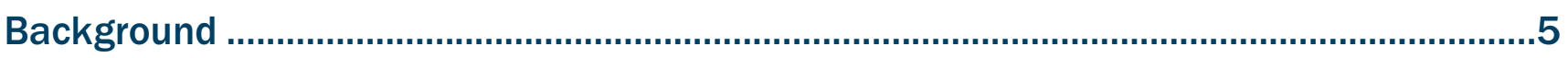

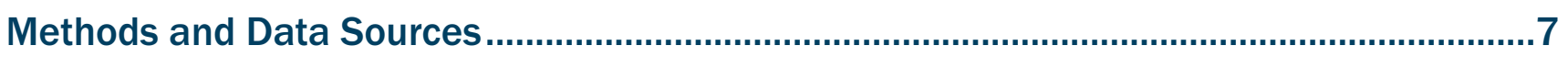

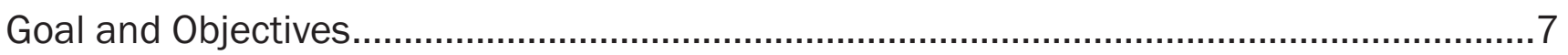

Definitions of Key Terms .............................................................................................. 7

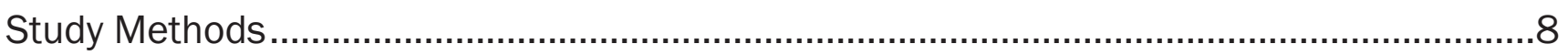

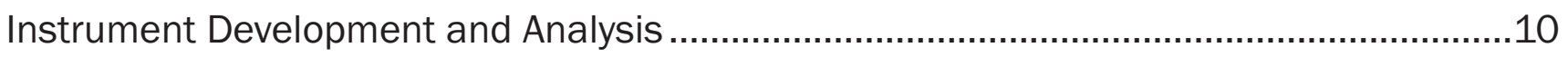

Ethical Considerations ....................................................................................................... 11

Limitations of Study ........................................................................................................

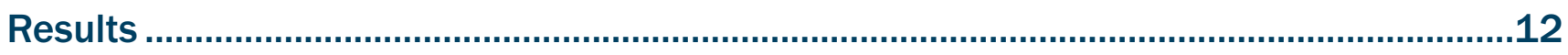

Legal and Policy Issues in Youth Vulnerabilities to HIV and Sexual Health Problems ........12

Patterns in Sexual and Health Seeking Behaviors and HIV-Related Discrimination ..........20

Factors in the Sexual-Risk and Health-Seeking Behaviors of Youth................................26

Qualitative Inquiries on HIV Youth-Focused Responses at the Individual, Institutional, and

Policy Levels...................................................................................................................29

Individual-Level Concerns and Responses..................................................................29

Macrosocial Service-Delivery-Level/Institutional Responses..........................................30

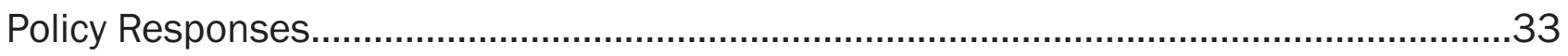

Youth Involvement in Program Implementation and Service Delivery...............................35

Key Institutional Actors in the Response to Youth Vulnerability to HIV/AIDS ......................35

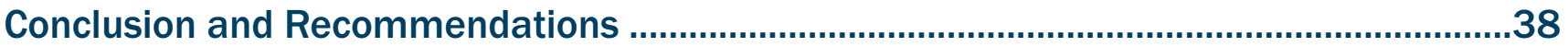

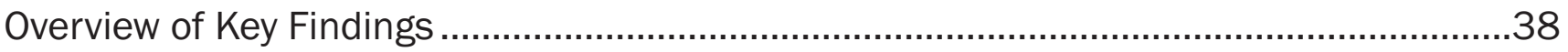

Legal and Policy Issues in Youth Vulnerabilities to HIV and Sexual Health Challenges....38

Patterns in Risk Behaviors and HIV-Related Discrimination...........................................38

HIV Youth-Focused Responses at the Individual, Institutional, and Policy Levels.............39

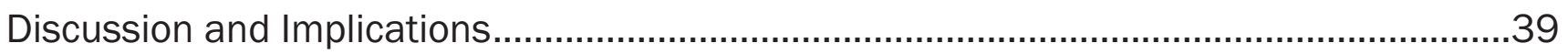

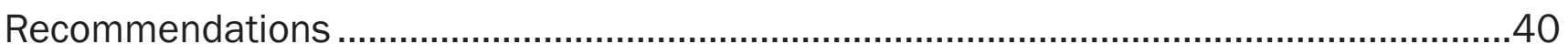

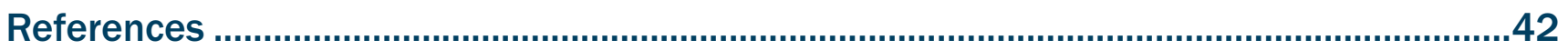

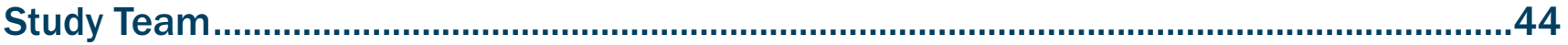




\section{LIST OF TABLES}

Table 1 Percentage of respondents aged 15-24 who used a condom at last sex among those with multiple partners in the past 12 months according to age and sex

Table 2 Relative risk ratios from logistics regression analysis of predictors of sexual debut on or before age 15 in Nigeria

Table 3 Relative risk ratios from logistics regression analysis of predictors of current sexual activity among never-married youth aged 15-24 in Nigeria

Table 4 Relative risk ratios from logistics regression analysis of predictors of condom use during last sex among sexually active youth who had multiple partners in the past 12 months in Nigeria

Table 5 Relative risk ratios from logistics regression analysis of predictors of comprehensive knowledge of HIV among respondents

Table 6 Key institutional actors responding to youth vulnerability to HIV/AIDS .36

Table 7 Proportion of HIV-funding allocation in Nigeria for youth interventions

\section{LIST OF FIGURES}

Figure 1 Population-based estimates of HIV prevalence among individuals aged 15-49, by sex and age

Figure 2 Among respondents aged 15-24, percentage reporting first sex on or before age 15, by location and sex

Figure 3 Among never-married respondents aged 15-24, percentage currently sexually active by location and sex

Figure 4 Among respondents who were sexually active in the past 12 months, percentage reporting having multiple sexual partners by age and sex.

Figure 5 Among respondents with multiple sexual partners in the past 12 months, percentage reporting condom use at last sex, by age and sex.

Figure 6 Percentage of respondents reporting ever being tested for HIV and having received the results, by age and sex.

Figure 7 Percentage of respondents reporting correct answers on all five indicators of HIV knowledge, by age and sex

Figure 8 Percentage of respondents that would not keep secret the HIV-positive status of a family member, by age and sex 


\section{Abbreviations/Acronyms}

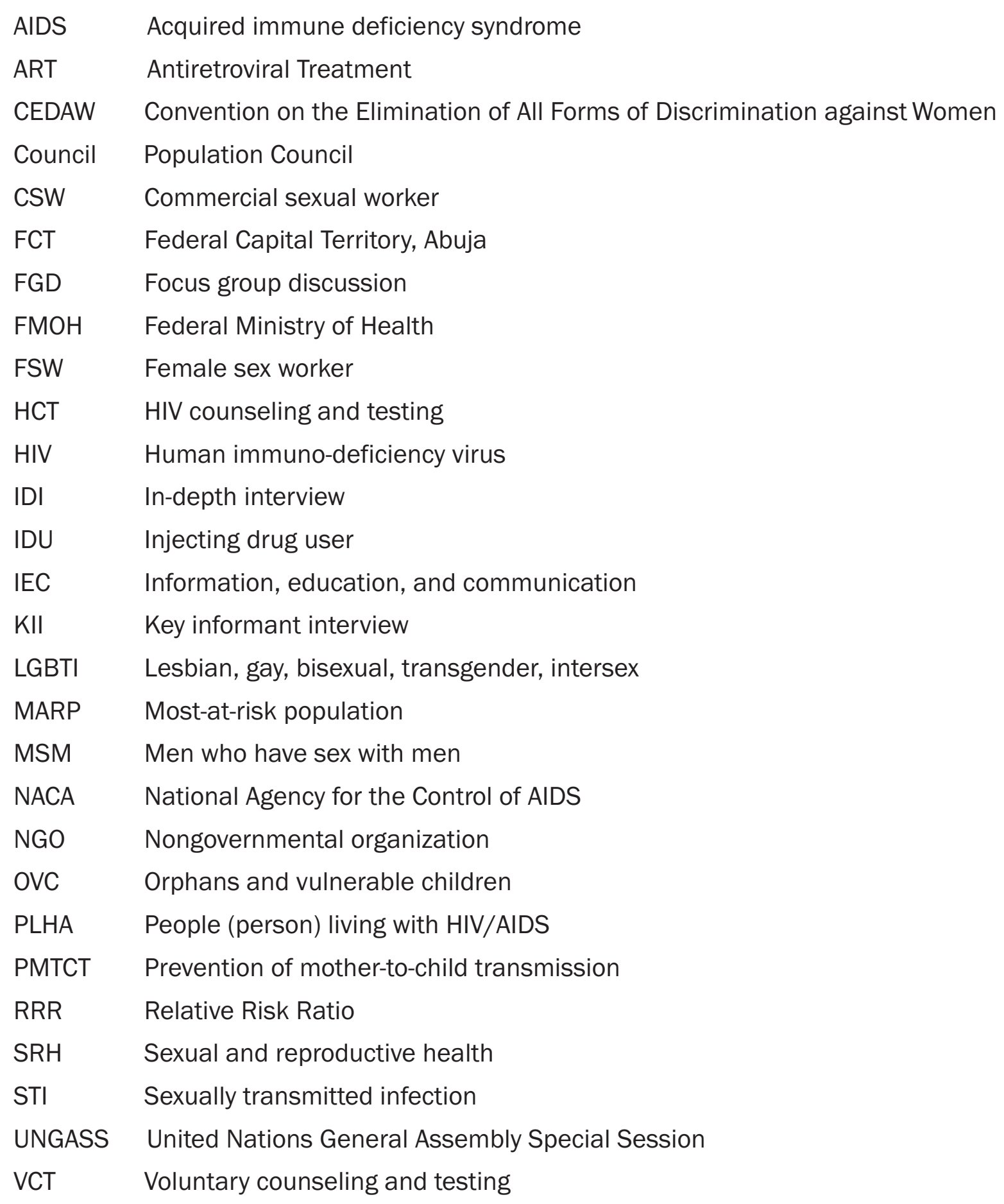




\section{Executive Summary}

This study, implemented between August 2011 and July 2012, sought to provide a comprehensive, evidence-based picture of the HIV-related issues facing Nigerian youth and the prevailing legal, policy, and programmatic responses. The study was designed to establish a basis for a sharper focus on youth within the national response to HIV.

Our researchers conducted an analytical review of the relevant literature on factors associated with HIV risk-taking and health seeking behaviours among young people aged 1524 in Nigeria. In addition, qualitative and quantitative analyses enabled an evaluation of the factors associated with young people's sexual risk behavior, HIV-related health-seeking behavior, and the extent of policy and programmatic involvement.

Between February and July 2012, the Population Council, in collaboration with leading sexual and reproductive health (SRH)/HIV-focused youth-serving nongovernmental organizations (NGOs) in Nigeria conducted the following qualitative inquiries:

Focus group discussions (FGDs), each made up of 6-12 participants

In-depth interviews (IDIs) with individualsperinatally infected with HIV; sex workers; orphans; married adolescents; and lesbian, gay, bisexual and transgender (LGBT) individuals. The participants represented an age- and gender-balanced population

- Key informant interviews (KIIs) with stakeholders in the arena of policies and programs regarding SRH/HIV-related issues facing youth.

The quantitative analysis consisted of secondary analyses of national HIV/SRH-related survey datasets, including the National HIV/AIDS and Reproductive Health Survey 2007; the Nigerian Demographic and Health Survey (DHS) 2008; and the Integrated Biological and Behavioral Surveillance Survey 2010. Multivariate analyses using logistic regression were conducted, with all regressions weighted to generate relative risk ratios and associated cluster-robust standard errors.

\section{MAIN FINDINGS}

\section{Responsiveness of National Laws and Policies}

Identifiable components that exacerbate young people's vulnerabilities to HIV/AIDS include: inconsistent definitions of youth/children, non-domestication of key international and regional protocols, inadequate enforcement of existing protective provisions or policies, the presence of punitive and repressive laws affecting stigmatized and vulnerable groups, and silence, denial, or neglect of particular sensitive issues. Where protective laws do exist, there is often a lack of enforcement or the existence of legal pluralism in which multiple and contradictory legal regimes (i.e., civil, customary, Islamic) coexist. There is also the added complication of Nigeria being a federal republic where each state has the autonomy to draft 
its own individualized legislation, leading to the presence of contradictory laws that negatively impact the vulnerabilities of young people. Most survey respondents thought that existing laws and policies did not promote the well-being of young people living with HIV and those involved in sex work, injecting drug use, and same-sex practices. Although men who have sex with men (MSM), female sex workers and injecting drug users are mentioned as a vulnerable group within national HIV/AIDS policies, social stigma and criminalization of sex work and homosexuality and drug trafficking laws create a disenabling environment to effectively reach young most-at risk populations (MARPs).

\section{Youth Focus in Policies and Program Strategies}

National AIDS and related policies contain very few youth-specific and youth-centered provisions. Nigeria has developed a national HIV strategic plan that forms a basis for the HIV response. Overall, the national strategic plan targets youth as part of the general population. The main concern expressed by stakeholders in Nigeria was poor implementation of existing youth-specific service-delivery guidelines due to unavailability of funds. Another factor contributing to poor youth involvement in policies and programs was the lack of awareness of, and/or poor training on, the use of existing guidelines by service providers and program managers. People living with HIV face high levels of stigma and discrimination and often fear disclosure as Nigeria lacks an anti-stigma and discrimination law at the national level with only a few states passing protective legislature.

\section{Sexual-Risk and Health-Seeking Behaviors}

This study identified risky sexual behaviors in both male and female youth. In Nigeria, a higher proportion of young women than young men reported sexual debut on or before the age of 15 (15.7\% vs 5.8\%). Among never-married respondents aged $15-24$ years, $14.1 \%$ of females and $11.2 \%$ males reported being sexually active. Self-reporting of multiple sexual partnerships was higher among males $(14.5 \%-17.9 \%)$ than females $(2.0 \%-2.3 \%)$ suggesting that behavioral interventions among youth would be incomplete without addressing this multiple partnership component and highlighting the need for all youth to have access to SRH services and comprehensive sexuality education. Among those having multiple sexual partnerships, more young men acknowledged using a condom during last sex in the past year than their female peers (56.4\% vs $29.0 \%)$.

The low level of condom use among Nigerian youth is particularly worrisome given the relatively high levels of high-risk sexual behavior. Increased condom messaging and distribution, and the inclusion of condom/sexual negotiation skills in youth sexuality education/HIV prevention programs, are essential.

Less than 35\% of youth had comprehensive knowledge of HIV/AIDS as constructed through a composite of the five United Nations General Assembly Special Session (UNGASS) indicators for HIV knowledge, and more urban than rural youth had comprehensive knowledge of HIV. Moreover, uptake of HIV testing remained low among youth in Nigeria ranging from $3.8 \%$ to $14.7 \%$ of young people having had an HIV test and received the test result. 


\section{Factors Associated with Sexual Risk and Health-Seeking Behaviors among Youth}

\section{Risky sexual behavior}

Variables significantly associated with having sexual debut before or at age 15 in the logistic regression analysis included being female (compared with being male), and residing in an urban location (compared with rural). The likelihood of having sexual debut before or at age 15 however respectively reduced with increasing educational status and with increasing household wealth quintile.

\section{Condom use during last sex among youth in multiple sexual partnerships}

Compared to their male counterparts, female youth with multiple sexual partners were significantly less likely to use condoms during their last sexual intercourse. Also, though, educational status was associated with greater likelihood of engaging in multiple sexual partnerships, it was also associated with greater use of condoms during such high risk sex, compared with those without education.

Comprehensive knowledge

Compared with youth aged 15-19 years, those aged 20-24 years were slightly more likely to have comprehensive knowledge of HIV. Female youth were also less likely to have comprehensive HIV knowledge compared to their male counterparts. Education (Tertiary; RRR: 3.801; Secondary; RRR: 2.554; Primary; RRR: 1.486; compared with No education) and wealth (Fifth quintile; RRR: 2.139; Fourth quintile; RRR: 1.861; Third quintile; RRR: 1.627; Second quintile; RRR: 1.413 compared with the first quintile) were significantly associated with comprehensive knowledge. These findings are plausible because being in upper socioeconomic class almost certainly guarantees better education, which impacts knowledge.

\section{HIV Youth-Focused Responses at the Individual, Institutional, and Policy Levels}

Individual level

At the individual level, the qualitative inquiries showed that most young people considered $\mathrm{SRH}$ to be a significant need among youth. Despite their consideration of SRH as a priority, youth overwhelmingly felt disempowered to adequately respond to their HIV and SRH vulnerabilities because of inadequate knowledge, issues with service providers and set-up of services, and livelihood struggles. Respondents often mentioned service-provider issues such as stigmatizing attitudes and a lack of confidentiality and competence as deterrents to young people's seeking HIV and SRH services, especially in public health facilities. Limited real involvement exists in the planning, delivery (beyond peer information, education, and communication [IEC]), and management of programs and services.

Institutional and policy levels

Institutional responses at the community and national levels continue to fall short of the needs and expectations of young people in the areas of HIV and SRH education and access to youth- 
friendly services, especially for the most vulnerable groups. The failures of institutional responses can be tied to the broader issue of denial and lack of openness about youth sexuality. Participants stated that sex education in primary and secondary schools only covers a narrow set of topics, mostly limited to abstinence. Condom use, family planning, and HIV counseling and testing (HCT) appear not to be taught, yet study participants viewed them as important in taking preventative action. For out-of-school-youth, HIV and SRH information is obtained through community channels such as community outreach activities, peer education, and seminars which may only reach a very small proportion of such youth.

Interviews with key stakeholders and program managers reveal that few high-quality SRH and HIV policies exist for youth, but inadequate resourcing (funding, infrastructure, personnel, and supplies) of programs and services, especially for rural and poor urban youth, out-of-school youth, and young key populations, severely limits their overall impact.

\section{RECOMMENDATIONS}

- Improving sexual health-seeking behaviors, especially uptake of HCT and condom use by all youth, through a combination of youth-accessible communication channels, is imperative.

- Evidence-based advocacy needs to be targeted at policymakers and donors to bring greater attention to the youth dimensions of the HIV epidemic, especially in relation to neglected vulnerable youth.

- Innovative operational research is called for to better understand how to increase the meaningful involvement of young people in the conception, planning, and implementation of SRH and HIV/AIDS policies and programs.

- Efforts to promote the mainstreaming of youth-friendly SRH and HIV services are required given the challenges of scaling up and sustaining the few model stand-alone services provided largely by nongovernmental organizations (NGOs).

- A strong case exists for systematic domestication of key international regional protocols.

- Alignment of national and subnational laws and of civil, customary, and religious laws need to be advocated for strongly to ensure that laws and policies are not contradictory, and implementation of existing youth-specific laws and policies need to be improved.

- The National Agency for the Control of AIDS (NACA) must live up to its oversight function of ensuring that young people are not neglected in national HIV policies and programs.

- The government needs to increase funding and demonstrate ownership and sustainability of youth-based HIV programs. 


\section{Background}

Nigeria, a country, home to over 162 million people, has a disproportionately youthful population with $31.7 \%$ of Nigerians aged between 10 and 24 years. ${ }^{1}$ Nigeria is facing a generalized HIV epidemic with an HIV prevalence of 3.6\% which translates into the second highest number of infections in the world. ${ }^{2}$ In 2010, nearly half of the 3.1 million Nigerians living with HIV were between 15 and 24 years old. ${ }^{3}$ Young women aged $20-24$ bear the greatest burden with an HIV prevalence of $4.5 \% .^{2}$

Figure 1: Population-Based Estimates of HIV Preavalence Among Individuals Aged 15 - 49, By Sex and Age

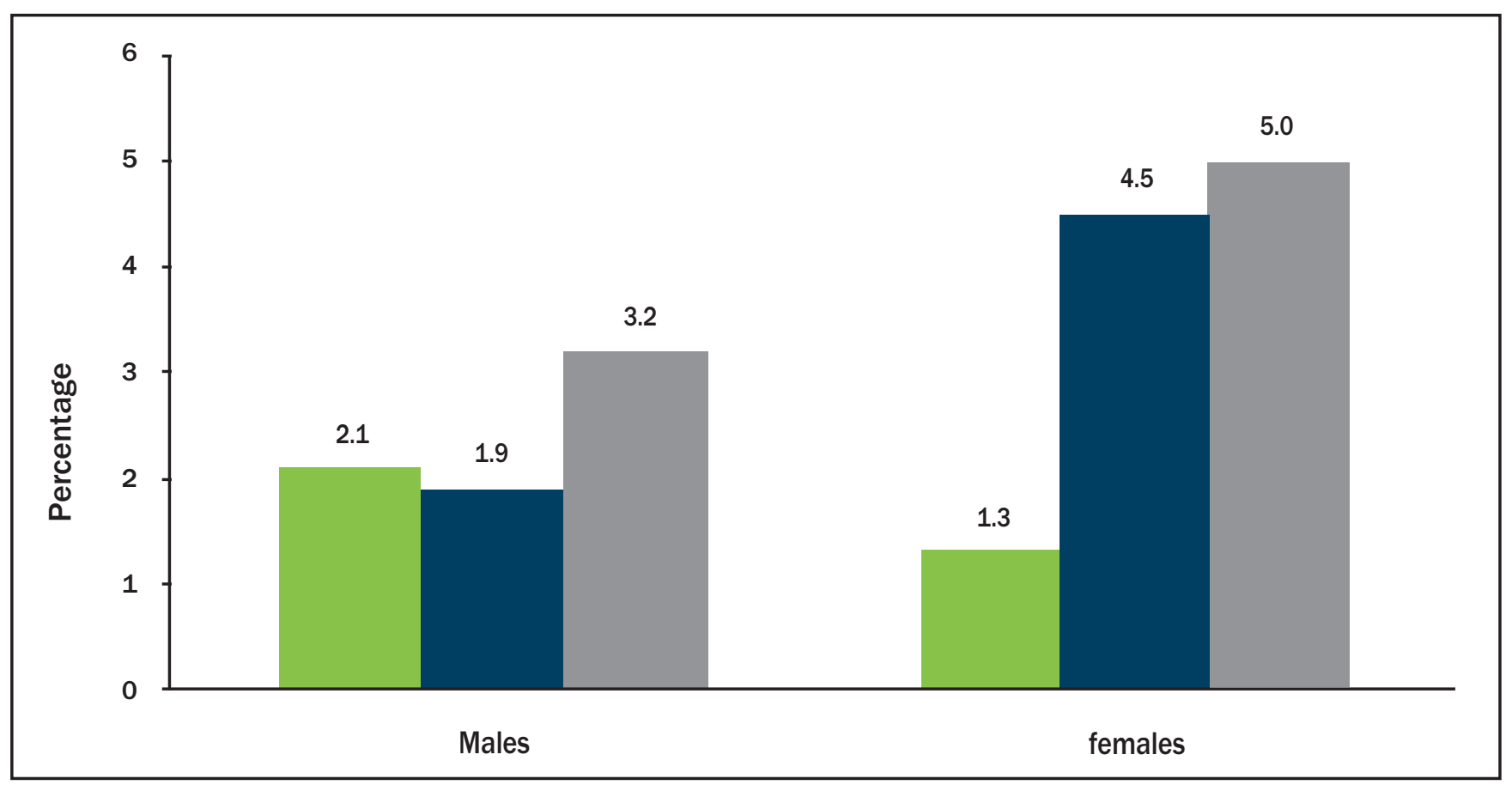

Age 15 - $19 \square$ Age 20 - $24 \square$ Age 15 - 49

Source: FMOH 2008

These broad statistics, however, mask huge variations in HIV prevalence and its impact among different subgroups of young Nigerians, who represent a highly heterogeneous population. Factors that may affect HIV exposure and impact include gender, marital status, level of education, employment status, rural-urban residence, migration status, sexual activity, living arrangements (with one, two, or no parents), HIV status, age, nationality, legal contexts, religion, and household economic status. ${ }^{4}$

Adolescents and young adults constitute about one-third of the total population of Nigeria, and their well-being is intricately tied to the country's prospects for sustainable development. ${ }^{5}$ Without accurate and timely evidence, policymakers and program planners/managers will not be able to properly plan, design, or allocate resources to monitor and evaluate policies and programs that effectively address the HIV prevention and impact-mitigation needs (including stigma and discrimination) of the various categories of youth across Nigeria. Generating such 
evidence would positively affect the course of the epidemic in Nigeria, since trends and patterns in HIV prevalence among young people tend to significantly shape overall trends in new infections.

A recent study commissioned by $\mathrm{UNAIDS}^{6}$ showed that although young people across Africa still account for about 40 percent of new infections, they also tend to lead the process of wider adoption of safer-sex behaviors in countries that have experienced recent, significant declines in HIV prevalence. Current funding mechanisms in Nigeria are geared towards strengthening health care facilities and community programs to provide quality HIV prevention programs to meet the needs of all. However, because they fall short of being youth-friendly in design and implementation, youth fail to access these services which further worsens their vulnerability to HIV/AIDS.

Evidence-based alignment of policies and programs is needed at the state and national levels to address the fundamentally "youthful" character of the HIV epidemic and its inherent diversities. However, there is a dearth of robust youth-related data that are sufficiently disaggregated to shed enough light on specific vulnerabilities, including stigma and discrimination that young people face, especially for the most vulnerable subpopulations such as MSM and LGBTI, female sex workers, married adolescents, orphans, IDUs, prisoners, migrants, youth displaced by conflict, and youth born or living with HIV.

Additionally, since there is limited data on the factors associated with HIV among Nigerian youth, the HIV response coordination mechanism remains ill-equipped to deal with the burgeoning HIV burden among youth. It will be particularly useful to provide quantitative and qualitative data to highlight the HIV vulnerabilities of youth across Nigeria and to strengthen the evidence base for a focus on youth in the national HIV response. 


\section{Methods and Data Sources}

\section{GOAL AND OBJECTIVES}

The goal of this study is to provide a comprehensive, evidence-based picture of the HIV-related issues facing young people in Nigeria and the prevailing legal, policy, and programmatic responses so as, to establish a basis for a sharper focus on youth within the response to HIV in the country.

\section{Objectives:}

Assess the extent to which relevant national policies, program strategies, and regional protocols are responsive to the HIV vulnerabilities of young people;

Critically highlight the degree to which national HIV and SRH-related laws discriminate against young people and thwart their ability to access HIV and other sexual-health information and services and legal protection when violations occur;

Examine empirically the vulnerabilities of youth to HIV and AIDS in Nigeria with regard to:

a. SRH and HIV risk, related health-seeking behaviors, and their social, cultural, economic, and legal determinants; and

b. the forms and nature of HIV stigma and discrimination that youth face and the consequences for their access to health and other services;

Document the extent to which the needs, concerns, and perspectives of youth are addressed in ongoing national HIV programs, and whether youth are meaningfully engaged in the planning, implementation, and evaluation of HIV programs; and

Identify key institutional stakeholders, at national levels, actively engaged in HIV/SRHrelated policies and programs for young people.

\section{DEFINITIONS OF KEY TERMS}

Access to HIV Services: Tested for HIV in the past 12 months and received the results.

Age at Sexual Debut: The age at first sexual intercourse.

Comprehensive Knowledge of HIV: Knowing that consistent use of condoms during sexual intercourse and having just one HIV-negative, faithful partner can reduce the chances of HIV infection, knowing that a healthy-looking person can have HIV, and rejecting the two most common local misconceptions about HIV transmission and prevention - that HIV can be transmitted by mosquito bites and that HIV can be transmitted by supernatural means.

Condom Use During Last Sex: Use of a condom during the last sexual intercourse

Discrimination: Obtained by proxy through respondents' admission of the following: (a) knowing someone who has been denied services because of his/her HIV serostatus, (b) knowing someone who has been denied involvement in social events because of his/her HIV serostatus.

Multiple Sexual Partners: Having sexual intercourse with more than one sexual partner in the past 12 months. 
Sexually Active: Had sexual intercourse within the last 30 days.

Risky Sexual Behaviors: We considered the standard definition of 'high-risk' sex used in all the surveys as inadequate for rigorous analysis as it basically regards all forms of sexual intercourse by unmarried sexually active youth (except with a partner they are living with) as 'high risk'. We therefore approached risk sexual behavior through three more robust proxy indicators (based on adequacy of numbers across cells of generated tables) than the adopted survey definition of high risk sex as sex with a nonmarital, non-cohabiting partner over the past 12 months. These three proxies are sexual debut before age 15, current sexual activity among unmarried youth, and engagement in multiple sexual partnerships in the past 12 months among sexually active youth.

Stigma: Obtained by proxy through expression of the following attitudes: (a) wanting to keep secret that a family member has HIV, (b) unwillingness to care for someone with AIDS, (c) unwillingness to buy fresh vegetables from a shopkeeper who has HIV, (d) saying that a teacher with HIV who is not sick should not be allowed to continue teaching.

Youth: The concept of youth varies across cultures and societies and the definition changes in response to the context, shifting to accommodate fluctuating political, economic, and sociocultural realities. The age range of $15-24$ is often used by the United Nations and other international organizations for ease of statistical comparison. In the context of HIV prevention and an exploration of the vulnerabilities of youth, young people aged 10-24 are pivotal because life skills, specifically safer-sex practices, acquired through this age range can positively influence the transition from adolescence to adulthood. ${ }^{7}$ This age group is also thought to be particularly vulnerable to sexual coercion. However, this study only focused on youth ages 15-24 because of the minimal data available on vulnerabilities among 10-14-year-olds. The terms "youth," "young people," and "adolescents" are used interchangeably in this report and all refer to the age group 15-24.

\section{STUDY METHODS}

\section{Literature Review}

The Council conducted a Nigeria-specific analytical review of relevant literature by using a standardized organizing frame focusing on factors associated with HIV risk-taking and healthseeking behaviors among adolescents across Nigeria. The empirical evidence on HIV-related stigma and discrimination among and toward young people, which is usually measured compositely through responses to questions on attitudes and intentions toward people living with HIV and AIDS, was also reviewed.

\section{Legal and Policy Assessment}

Gender equity and rights-based content analyses and reviews of relevant national laws, policies, and program strategy documents were conducted to ascertain:
a. The extent to which these laws and policies recognize, respond to, and address the HIV prevention and impact-mitigation needs and perspectives of young people in all their diversities (age, marital status, HIV status, employment status, sexual orientation, etc.); and
b. Whether the laws and policies elevate or reduce the exposure of young people to 
HIV infection and SRH problems and related stigma and discrimination by the way they treat issues such as:

- age of consent (for sex, marriage, and SRH/HIV services)

- sexual abuse (rape, incest, etc.)

- violence against women

- access to safe abortion services

- legal status of sex work

- trafficking of girls and young women

- HIV-related stigma and discrimination

\section{Secondary Analyses of National Survey Datasets}

a. The Demographic and Health Survey (DHS) 2008, Integrated Biological and Behavioral Surveillance Survey (IBBSS) 2010, and the National HIV/AIDS and Reproductive Health Survey(NARHS Plus) 2007 survey datasets were analyzed to discern the risk behaviors, health-seeking behaviors, and HIV-related stigma and discrimination among young women and men aged 15-24.

Statistical analysis of the national HIV/SRH-focused behavioural survey datasets included: the key dependent variables --- risky sexual behaviours (measured via sexual debut before age 15, current sexual activity among never-married youth, and multiple sexual partnerships among sexually active youth) age at sexual debut, condom use, uptake of HIV testing, and attitudes towards persons living with HIV; and the key social and economic characteristics-age, marital status, formal schooling status, residential milieu, household economic status, and employment status, among others to the extent allowed by the available data. Marital status, living arrangement, and religion were not included in the multivariate analysis because the sample sizes for married youth surveyed in all the datasets were relatively small and the distributions were highly skewed for these variables.

As discussed previously, the work focused on youth aged 15-24 because of the dearth of data on the vulnerabilities among 10-14 year-olds. However it was possible to use information from those aged 15 and older to document experiences from earlier ages.

b. Multivariate analyses using logistic regression were conducted to determine the key social and economic factors associated with the following key dependent variables: risky sexual behaviors (measured via sexual debut before age 15, current sexual activity among nevermarried youth, and multiple sexual partnerships among sexually active youth) and comprehensive knowledge of HIV. The independent variables were these key social and economic characteristics: age, marital status, educational status, residential milieu,household economic status, and employment status, among others to the extent allowed by the available data.

\section{Qualitative Inquiries}

Focus group discussions (FGDs), in-depth interviews (IDIs), and key informant interviews (KIIs) 
were conductedin Kano, Lagos, and the Federal Capital Territory (FCT) by the Population Council in collaboration with the foremost youth-serving SRH/HIV NGOs focused in these states. Young people were recruited for FGDs to achieve diversity regarding age, gender, sexual orientation, schooling, and marital and HIV status. Eleven FGDs (each made up of 9-12 participants) were conducted.

IDIs were conducted to document young people's experiences and the lessons they learned about accessing HIV and related SRH services, including preventing mother-to-child transmission (PMTCT). Interviews were conducted with young people balanced by gender and age across several categories: persons perinatally infected with HIV, men who have sex with men (MSM), and married adolescents. Credible youth-serving NGOs and HIV service providers assisted the country research team in identifying potential participants.

The key informant interviews (KIIs) targeted stakeholders with policy and/or programmatic experience regarding the salient SRH/HIV-related issues facing youth. Stakeholders interviewed included program managers, peer educators, youth leaders, HIV service providers, and legal advocates. Representatives of key international and national organizations involved in the HIV response in Nigeria were also interviewed, including funding agencies (USAID, the World Bank, and the Ford Foundation), relevant agencies of the United Nations (UNAIDS, UNFPA, and UNICEF), and the National Agency for the Control of AIDS (NACA), and managers of major HIV service-delivery programs or projects, and SRH- and HIV-focused governmental and nongovernmental organizations serving youth. Respondents were selected based on consultations with Ford Foundation program staff, and recommendations from experienced professinals and researchers in the SRH and HIV fields in Nigeria, and were selected to achieve diversity regarding gender, sectoral/professional background, and geographic location.

\section{INSTRUMENT DEVELOPMENT AND ANALYSIS}

Standardized interview guides were developed in a collaborative, iterative process coordinated by the multi-country project team through a joint review by the Population Council country technical leads and Ford Foundation program staff. The FGD guide explored participants' experiences with accessing SRH and HIV prevention, treatment, care, and related educational and legal services, including issues regarding distance and location, provider attitudes, and cost of services. IDIs explored personal experiences with using services, quality of care (especially in relation to stigma and discrimination), and youth participation in program development and service delivery. The KIls explored the following major themes: allocation of resources toward the youth dimensions of the HIV response, policy and service delivery gaps, social and legal barriers to youth access to comprehensive HIV services, and recommendations regarding how to better target HIV/SRH programs and services to youth.

Trained researchers facilitated the group discussions in English and Hausa for the discussions held in Kano. The interviews were tape recorded, translated, where necessary, transcribed verbatim, and analyzed using QSR Nvivo 9 Software (International Pty 2007). ${ }^{8}$ In total, 6 FGDs, 29 IDIs, and 14 KIls were conducted. 


\section{ETHICAL CONSIDERATIONS}

The study was approved by the Institutional Review Boards of the Population Council and the Nigerian Institute of Medical Research (IRB-NIMR). Concerns about participants' confidentiality and safety made it preferable to conduct interviews at central venues. For similar reasons, participants were asked to provide pseudonyms during FGDs, which they were encouraged to use when referring to other participants. Study participants taking part in FGDs and IDIs were given transport reimbursement and refreshments were provided.

\section{LIMITATIONS OF STUDY}

A few limitations are worth noting. First, although the selection of different groups of youth and stakeholders according to predefined criteria enabled the study to capture a range of experiences, the samples, particularly the qualitative samples, may not be representative of all young people and actors in the SRH and HIV contexts in Nigeria. Second, the reported norms and experiences may be specific to particular local contexts, making difficult the generalization of findings to other contexts within Nigeria. Nonetheless, the breadth, depth, and multiplicity of data sources and types give us appreciable confidence in the robustness of the findings and conclusions. 


\section{Results}

\section{LEGAL AND POLICY ISSUES IN YOUTH VULNERABILITIES TO HIV AND SEXUAL HEALTH PROBLEMS}

\section{Responsiveness of National Laws and Policies}

Although the legislative and policy milieu in Nigeria includes provisions that alleviate and are responsive to young people's vulnerabilities to HIV and SRH morbidity, they also have components that exacerbate these vulnerabilities. These failures occur along the following broad lines: inconsistent definitions of youth/child, non-domestication of key international and regional protocols, inadequate enforcement of existing protective provisions or policies, and presence of punitive and repressive laws affecting stigmatized and vulnerable groups.

Despite being a signatory to several key international and regional protocols (e.g., the African Charter on Human and People's Rights, CEDAW, Maputo Protocol) that have the potential to reduce the HIV-related vulnerabilities of young Nigerians, Nigeria has failed to domesticate them or has laws that violate such treaties and protocols. For example, Nigeria is signatory to the Convention on the Rights of the Child, yet it has only partially domesticated its provisions with only a few states ratifying them. Despite being signatory to CEDAW, sexual offense laws in Nigeria do not contain provisions for marital rape yet according to the 2008 NDHS, 3\% of married women between the ages of 15 and 49 have experienced spousal rape. ${ }^{9}$ This allowance for forced sex within the realm of marriage further marginalizes vulnerable married young women and girls, limiting their negotiating power for safer sex practice within marriage and violating their right to bodily integrity.

Where protective laws do exist, they are often not enforced. An example of poorly enforced laws is the criminalization of sexual assault. The law criminalizes rape and stipulates penalties of 10 yearsto life imprisonment as well as fines of 200,000NGN for those convicted of rape, but societal stigma against rape victims reduces both the number of rapes reported and the penalties meted out for conviction. ${ }^{10}$

Additionally, legal pluralism exists, wherein multiple and often contradictory legal regimes (i.e., civil, customary, and religious) coexist. Federalism is an added complication whereby each state has autonomy to draft its own individualized legislation. Such circumstances are of particular consequence for age at marriage/forced marriage among girls, age of consent, and access to services. For example, despite the Child Rights Act, passed in 2003 by the national legislature, having raised the minimum age of marriage to 18 for girls, Nigeria, particularly northern Nigeria, continues to have some of the highest rates of child marriage in the world. ${ }^{11}$ According to the 2008 NDHS, 39.4\% of women aged $20-24$ had been married by age $18 .{ }^{9}$ In Nigeria, federal law may be implemented differently at the state level, and to date, only 16 of the country's 36 states have ratified the Child Rights Act's provisions. Furthermore, Nigeria's legal pluralism and the fact that state and federal governments have control only over marriages that take place within the civil system but not under the customary and Islamic laws leave room for manipulation of the law. Nigerian customary law does not generally have any lower age limit for betrothal and girls may be betrothed at an early age sometimes from birth.

Legal pluralism is also significant in maintaining a sociocultural environment that heightens 
the HIV/SRH vulnerabilities of young Nigerian women and girls. The 1999 Constitution of Nigeria prohibits discrimination on the grounds of gender but customary and religious laws continue to restrict women's rights. Gender inequity limits women's access to appropriate HIV and SRH information and services as well as hinders their negotiating power in sexual relationships which exacerbates their innate biological vulnerabilities to HIV and other SRH morbidity. Specifically, Nigerian women and girls face inequity in terms of exposure to gender based violence, ownership rights and civil liberties.

There are no national laws criminalizing gender based-violence, and some federal laws allow violence against women (US Department of State, 2011) ${ }^{12}$. For example, the penal code allows husbands to use physical means to censure their wives as long as it does not cause "grievous harm," which is defined as loss of sight, hearing, speech, facial disfigurement, or life-threatening injuries. ${ }^{12}$ Penalties for the sexual assault of a man exceed the penalties for the same offense against a woman. ${ }^{12}$ Only five out of thirty six states have laws (Ekiti, Ebonyi, Jigawa, Cross River, and Lagos) aimed at punishing domestic violence. ${ }^{12}$

Section 43 of the Nigerian constitution allows both male and female Nigerians to own and acquire movable and immovable property but despite this a large proportion of women in Nigeria are prohibited from owning land or inheriting property by customary laws of inheritance.$^{13}$ For example, civil law enables women to own land but certain customary laws maintain that only men have the right to own land. Under civil and Islamic law, married women are entitled to own property other than land but customary law denies them any entitlement to household property or to assets acquired by their husbands. Financial inequities faced by women limit their access to sexual and reproductive health services, exposes them to transactional sex, and can hinder their ability to negotiate for safer sex practices in their sexual relationships with male partners.

Restrictions to the civil liberties of women also include limitations on their freedom of movement. ${ }^{13}$ Purdah, which is practiced within Muslim communities in some northern states, does not allow women to leave their homes without permission from their husbands and women must be accompanied by a man at all times when in public. This practice limits women's access to sexual and reproductive health services.

In Nigeria, laws exist that are considered repressive and punitive to most-at-risk populations (MARPs) such as sex workers, drug users, and MSM. Sex work is criminalized under the Penal Code which operates in northern Nigeria, the Criminal Code which is utilized in the south and Sharia law. Despite such restrictions, there are approximately one million female and some male sex workers in Nigeria. ${ }^{14}$ Sex workers in Nigeria are characteristically female, poor, marginalized and stigmatized. Criminalizing sex work exacerbates the HIV risks faced by sex workers because it decreases their negotiating power with clients, many of whom place a premium on unprotected sex..$^{15}$ It also stops them from accessing medical services adequately because they fear discrimination and stigma.

Same-sex practice is also criminalized in Nigeria. Criminalization exacerbates homophobia and places sexual minorities, especially MSM, at greater risk of violent attack and HIV infection, because they are forced to conduct their relationships clandestinely and are less free to seek medical treatment and sexual and reproductive health services. ${ }^{16} \mathrm{Currently}$ MSM have an estimated HIV prevalence of about $17.2 \%$ and are considered a most-at-risk 
population by the national HIV response. ${ }^{17}$

\section{Youth Focus in Policies and Program Strategies}

National AIDS and related policies contain several noteworthy gaps and inconsistencies with regard to the treatment of youth and their particular vulnerabilities and needs. First, the definition of "youth" in Nigeria is problematic because most definitions are not in line with internationally accepted parameters. In the UN system, youth is defined as someone aged 15 to 24 years old. The Second National Youth Policy defines youth as "young males and females aged 18-35 years." The policy admits to the age range being "broad" but stands by this definition stating that "the male transition to adulthood, in terms of achieving the economic and social stability that comes with steady employment, may extend into the late twenties and mid-thirties."

Secondly, many of the policies contain few youth specific provisions. For example, Nigeria has developed a national HIV strategic plan, the National HIV/AIDS Strategic Plan 2010 2015, that forms a basis for the HIV response. Most of the thematic areas of the strategic plan have provisions that target young people as part of the general population with only the thematic area of "Promotion of Behavior Change and Prevention of New Infections" specifically mentioning young people as a target of communication interventions. Thirdly, the few youth specific provisions in existence treat youth as a homogeneous population without a focus on key and other vulnerable populations.

\section{Specific National HIV/AIDS \& SRH Policies}

\section{The President's Comprehensive Response Plan for HIV/AIDS (PCRP) in Nigeria 2013}

The goal of the PCRP is to accelerate the implementation of key interventions over a two (2) year period and bridge existing service access gaps. The role of the PCRP is to "galvanize the national response to attain the targets set in the National HIV/AIDS Strategic Plan (2010-2015) and to focus and strengthen the national response to HIV/AIDS." The PCRP's main themes are improved coordination and systems strengthening of the national response and accelerating implementation of HIV prevention, care and treatment services in Nigeria.

The PCRP includes prevention interventions for young people and MARPs as a priority area and has objectives to reach 4 million young people with combination prevention services and strengthen local stakeholders to develop, manage, and evaluate effective services for young people and MARPS. In its priority area on HIV care and support, it aims to promote the survival and improve the quality of life of PLHA especially OVC.

The policy like its predecessors contains few youth specific provisions though it sets more ambitious targets. While, it includes "young people" as a subpopulation at greatest risk for HIV infection/transmission, it limits this definition to young women aged 20-24 and young men aged 24-29 neglecting adolescents who are at least as likely to be vulnerable as their older counterparts. This is out of step with available evidence. Although HIV prevalence is highest in these age groups, HIV exposure is also likely to be occurring at younger ages. 
Beyond a disaggregation by age, it remains silent on other hypervulnerable categories of youth like HIV positive youth, out of school youth, married female adolescents and young MARPs.

\section{National HIV/AIDS Strategic Plan (NSP) 2010-2015}

The goal of this policy is to reposition prevention of new HIV infections as the centerpiece of the national HIV and AIDS response. Thus greater focus will be placed on scaling-up HIV prevention services that enable individuals to maintain their HIV negative status as well as improve access to quality treatment and care services for PLHA including positive, health, dignity and prevention (PHDP) interventions that reduce their transmitting HIV to others. The policy's priority areas include the following: promotion of behavior change and prevention of new HIV infections; treatment of HIV and AIDS and related health conditions; care and support of PLHA, people affected by AIDS, and OVC; policy, advocacy, human rights, and legal issues; institutional architecture, systems, coordination, and resourcing; monitoring, evaluation systems comprising $M \& E$, research, and knowledge management.

One of twelve (12) key considerations of the NSP is young people's disproportionate infection with HIV. Only one (1) objective of the NSP focuses solely on youth (at least $80 \%$ of young people 15-24 years adopting appropriate HIV and AIDS related behavior). There are also three (3) orphans and vulnerable children (OVC) specific objectives centered on legal protection, gender-sensitive integrated care and support, and livelihood strengthening of older OVC, households, and community based initiatives. Lastly, major interventions under an objective focused on protecting women, children and other socially vulnerable and marginalized groups from HIV infection include: improved services for the protection of people who are vulnerable and marginalized (persons living with disability, out-of-school youth, OVC and MARPS) from HIV and to support Family Life and HIV education among youth that are in and out of school and are in urban, rural, and hard-to reach places.

The main gaps in this policy are that it has few youth-specific provisions and lack of segmentation of the youth population by risk and/or special needs with no mention of young key populations, youth living with HIV and other vulnerable youth like married female adolescents.

National Strategic Framework on the Health and Development of Adolescents and Young People in Nigeria 2007 - 2011

The goal of this policy is to facilitate the implementation of the National Adolescent Health Policy that aims to improve the quality of life of young persons in Nigeria. Its priority areas are sexual and reproductive health, nutrition, accidents, drug abuse, education, career and employment, social adjustment and parental responsibilities, rights, spirituality, and adolescent mental health.

It is the only policy that is focused solely on the health of Nigerians 10-24 years old and has sexual and reproductive health as one of its priority areas. Although it mentions, in its design of activities, some groups of youth with "special sexual and reproductive health challenges" like "married adolescents, people having sex with the same sex, OVC, physically and/or mentally challenged, almajiris, street children and young people in 
conflict situations, it still treats youth as a homogenous population and does not address the special needs of these populations. It acknowledges the role of early marriage, other harmful cultural practices, and sexual assault in increasing the SRH vulnerabilities of young people yet fails to address these issues in its SRH activities. The policy is also silent on youth living with HIV.

\section{Second National Youth Policy 2009}

The goal is to provide an appropriate framework that will promote the enjoyment of fundamental human rights and protect the health, social, economic and political wellbeing of all young men and women in order to enhance their participation in the overall development process and improve their quality of life. It has eighteen (18) Priority areas including "Youth and Health" and "Youth and HIV/AIDS."

The policy explicitly includes youth living with HIV/AIDS and female sex workers as priority target groups. It recognizes the increased vulnerability of young women and youth in AIDS affected families. Strategies include improving youth access to schooling, youth friendly health services, and counseling opportunities for decent livelihoods as a means of decreasing the risk of contracting HIV. It also mentions voluntary counseling and testing (VCT), sexually transmitted infections (STI) treatment, behavior change communication (BCC) and the promotion of abstinence and mutual fidelity messaging as strategies in dealing with the vulnerabilities of youth to HIV/AIDS.

The policy's definition of youth is broad including those aged 18 to 35 years old and leaving out younger adolescents. The policy also does not explicitly link its other priority target groups to HIV vulnerability e.g. street youth, out of school youth, and unemployed/underemployed youth, and it does not tailor its strategies to the needs of the different categories of vulnerable youth. It is also completely silent on the needs of sexual minorities and married youth.

\section{National Reproductive Health Policy 2010}

The goal of this policy is to provide the framework for actions and guidance for national and local initiatives aimed at ensuring the availability of and access to a full range of sexual and reproductive health information and quality services for all Nigerians so as to enable them attain optimal sexual and reproductive health and wellbeing throughout their life cycle. Its priority areas include the following: healthy pregnancy and childbearing, healthy sexual development and sexuality, infection-free sex and reproduction, achieving desired and intended fertility, including prevention of mistimed and unwanted pregnancies.

The policy provides a situation analysis of adolescent sexuality and reproductive health that highlights the high prevalence of unsafe sexual behavior and the resulting poor sexual and reproductive outcomes such as teenage pregnancy, unsafe abortions, and STIs among adolescents. It also includes adolescent-specific targets in regards to condom use and comprehensive knowledge, e.g. reduce the proportion of adolescents engaging in unprotected sex from $28 \%$ of males and $42 \%$ of females in 2007 to $10 \%$ or less for each sex by 2015.

The policy is limited in that it focuses on only adolescents as a vulnerable group and does 
not address older youth age 20-24. It also treats adolescents as a monolithic group without highlighting sub-groups with different needs and/or higher vulnerability such as adolescent sex workers, married adolescents, and sexual minorities.

\section{National Gender Policy}

The policy aims to promote gender equity and sustainable human and economic development in Nigeria. It has sixteen (16) thematic areas including gender-based violence, health and reproductive services, gender and HIV/AIDS, poverty and economic empowerment, employment and labor issues.

The National Gender Policy aims to strengthen and propel existing policies, which enhance child survival, protection, and development, and eliminate all forms of discrimination against the girl child; ensure equal access to primary and secondary education by all children irrespective of gender, physical condition, geographical location, and socioeconomic status of parents; increase female enrolment in science and technology education, especially at the tertiary level; and improve the demand and supply factors that hamper the girl child education. Despite its heavy emphasis on the girl child, in its HIV/AIDS focused objectives and strategies, the policy does not highlight the increased vulnerability of girls and young women to HIV/SRH issues than their older counterparts and does not include increased access to girl (youth) friendly SRH/HIV services as an intervention.

\section{OVC National Plan of Action 2006-2010}

The plan of action's goal is that by 2010 , mechanisms for the protection, care and support of orphans and vulnerable children are in place and facilitating the provision of basic services within a supportive environment from national to household level. Its thematic areas include protection, psychosocial care and support, education, healthcare, household care and economic strengthening, advocacy and social mobilization, legal and policy context.

The action plan recognizes the role of the HIV/AIDS epidemic in the growth in the numbers of AIDS - affected OVC and their increased vulnerability compared to other categories of OVC. The definition of OVC is very broad and includes sexually abused children, child sex workers, children living with HIV, married children, and children affected or orphaned by HIV/AIDS. The plan acknowledges that OVC have low knowledge of sexual health and safe sexual health practices and have a high prevalence of unprotected sex, unwanted pregnancy, abortion and STD and the policy makes recommendations that aim to remedy this situation. Despite acknowledging the hyper-vulnerability of OVC to HIV and other SRH morbidities, the only costed key action in the plan that addresses adolescents' vulnerability in this regard is to "train peer counselors at already established VCT centers at community 
level to support OVC in facilities for counseling." Additionally sexual minorities and children who use drugs are not included in the OVC definition.

\section{Perspectives on Policies}

In the qualitative inquiries, informants acknowledged the existence of some youth-specific provisions, policies and guidelines but had differing opinions on the extent to which these addressed the specific needs of youth and on the importance of having youth specific provisions, policies and guidelines. Some key informants felt that the broad policies were sufficient to address the HIV/AIDS vulnerabilities of Nigeria's youth.

"I am not sure we have any specific policies focusing on young people. Rather we have a policy that addresses the HIV scourge among the general populace and we know that virtually everybody is included in that framework. To that extent, I don't really believe we should have a separate policy for young people in terms of HIV/AIDS, although we have a national policy on adolescents and other young people which also addresses the issue of HIV/AIDS. There is no policy that is in isolation." (KII, staff of FMOH)

"If you talk of this adolescents' policy, it derives its formulation within the context of the national health policy, the HIV/AIDS policy and all the other national strategic frameworks so they dovetail into one another. But I believe, in terms of policy, I believe we have adequate policy to address the challenges of the young people in terms of HIV/AIDS and then the programmes, of course the programmes and services derive from the policy. I think, for now, with donor funding, I think, most of these programmes are being implemented especially donor funds. I believe they are being implemented." (KII, staff of FMOH)

Others were dissatisfied with the current state of affairs as indicated by the following quotes from two respondents.

\footnotetext{
“As we, know, the HIV policy serves as a statement of Nigeria's determination to reverse the tide of HIV and mitigate its impact on Nigerians. It also serves as a guide for a more coordinated response to the epidemic. One would therefore naturally have expected that a more clearly delineated youth response be accommodated in the national HIV response. Looking at the history of HIV policy in Nigeria, this has not been so." (KII, Head of SRH focused NGO)
}

"Yes. There should be specific youth policy devoted to HIV programs that target youth. These are the vulnerable groups and new HIV infections occur amongst these groups of young 
people.....There are policies on youth development in Nigeria e.g. Adolescent RH etc. But we need programs that specifically address youth and HIV/AIDS" (KII, Staff of donor agency)

\title{
Other concerns had to do with service providers' and program managers' awareness of existing guidelines. It was reported that few service providers and program managers may be aware of the existence of the guidelines. This was attributed to poor dissemination of information.
}

\begin{abstract}
"Well Nigeria has for a long time had problems with dissemination, you know there are lots of guidelines and if you go to the relevant departments in the ministries those guidelines are there but ....even when we ask for assistance from partners to develop these guidelines one of the things we neglect to do is cost for disseminating it." (KII, Staff of UN agency)
"Some of the local government officers work with us, they don't know jack about this (HIV they are completely blank, so somebody in the system may know, but not at that local government, maybe in the state government, maybe the PS (Permanent Secretary)." (KII, Head of youth focused NGO) guidelines specific to youth) and often times we call attention to some of those issues, and
\end{abstract}

Additionally, informants mentioned a need for values clarification in terms of youth sexuality by policymakers and pertinent institutions in order to obtain improved policy and program development.

\begin{abstract}
"I think the policy makers are living in their own world. On one hand, they think young people are not sexually active. On another hand, they think... hmm when you talk about youth, the definition of youth is up to 40 years, you lose the point. Then you lose from 10 to 25 [years] that should be focused on, because it's at that point that you can build their self-esteem. It's at that point that you can build a lot of skills in them, to make them even resist getting infected." (KII, Head of youth focused NGO)
\end{abstract}

"In the past our institutions shied away from addressing these issues regarding cultures and beliefs e.g. some hospitals cannot engage youth discussion of safe sex practices because these institutions shy away especially with HIV issues. We must come up with innovative ideas to talking about youth problems in terms of HIV/AIDS." (KII, Staff of donor agency) 


\section{Legally-Based Manifestations of HIV-Related Stigma and Discrimination}

The legal context for protection against HIV-related discrimination for youth in Nigeria does not enable the prevention and redress of discrimination experienced by HIV positive youth. The 2009 National HIV/AIDS Policy Review Report states that most of the HIV/AIDS-related policies protecting PLHA are not supported by appropriate legislation. ${ }^{17}$ In Nigeria there is a lack of political will or motivation to pass a national law to protect PLHA as evidenced by the fact that the Anti-Stigma and Discrimination Bill has remained stagnant in the National Assembly for the past five years, although a few states have passed similarly protective legislation. There is an anti-discrimination policy in the workplace but it insufficiently protects Nigerian youth as it does not apply to most of Nigeria's youth as most are unemployed due to the country's high rate of youth unemployment and the fact that its provisions do not apply to educational institutions. The 2009 National HIV/AIDS Policy Review Report also observes that there is limited evidence of implementation of workplace policies at all levels and widespread violations of confidentiality of HIV status, in particular among health workers, remains a major deterrent to voluntary testing. ${ }^{18}$

\section{PATTERNS IN SEXUAL AND HEALTH SEEKING BEHAVIORS AND HIV-RELATED DISCRIMINATION}

\section{Risky Sexual Behaviors}

Higher proportion of young women than young men in Nigeria reported sexual debut before the age of 15 (Figure 2). Among females 15-24 years of age, rural respondents reported sex before age 15 more than did urban respondents (20.2\% vs. $7.6 \%)$. Also, more young women than young men were likely to report first sexual experience at marriage and ever having sex. Age at first sex is an important indicator of sexual risk because it determines the first exposure to sexual infection and is a risk factor for HIV infection. Young men reporting sexual debut before age 15 were more likely not to use condoms at first sex and more likely to have had multiple and casual sexual partners. ${ }^{19}$

Indeed, the same pattern emerges from the data on current sexual activity among nevermarried youth aged 15-24 (Figure 3). The female respondents consistently reported much higher rates than their male counterparts. 


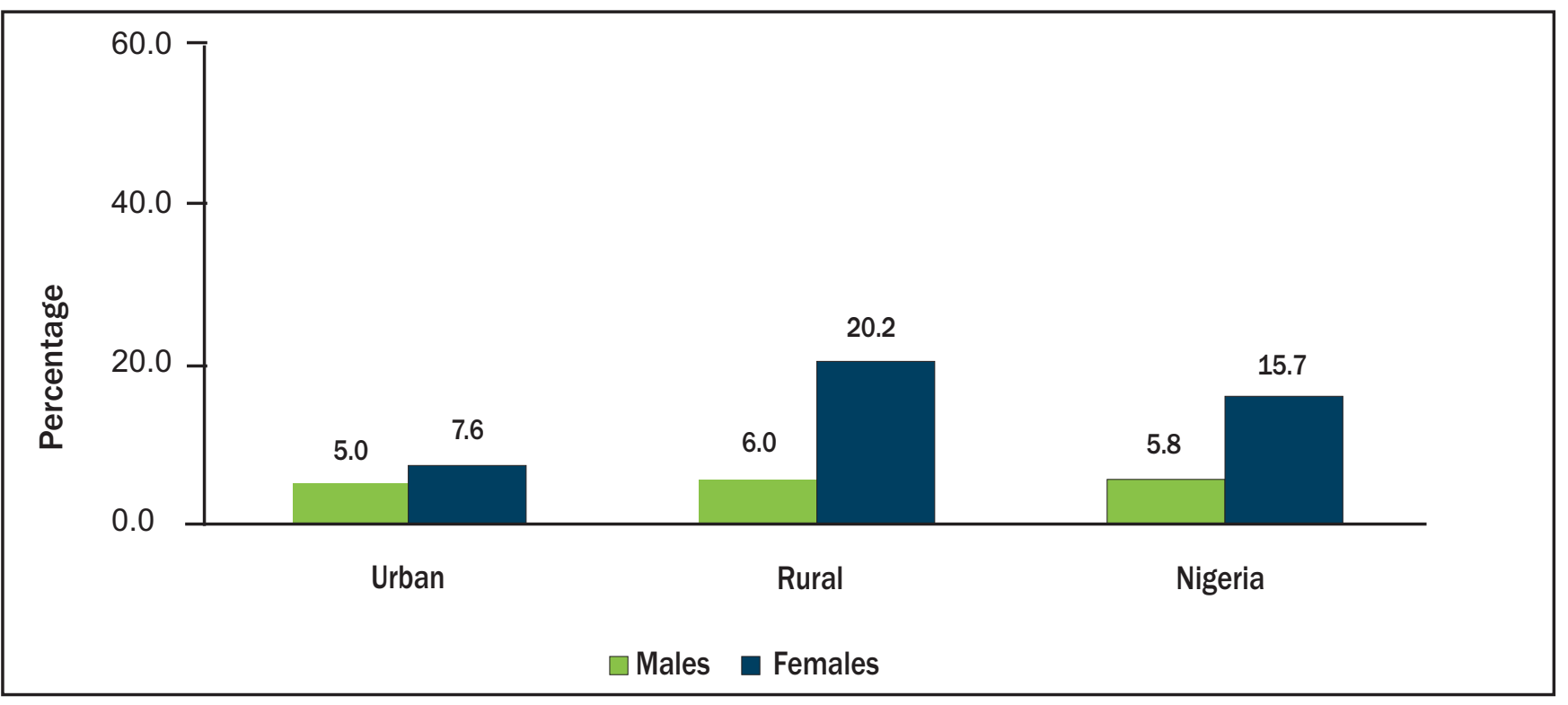

Data source: DHS 2008

FIGURE 3: AMONG NEVER-MARRIED RESPONDENTS AGED 15 - 24, PERCENTAGE CURRENTLY SEXUALLY ACTIVE BY LOCATION AND SEX

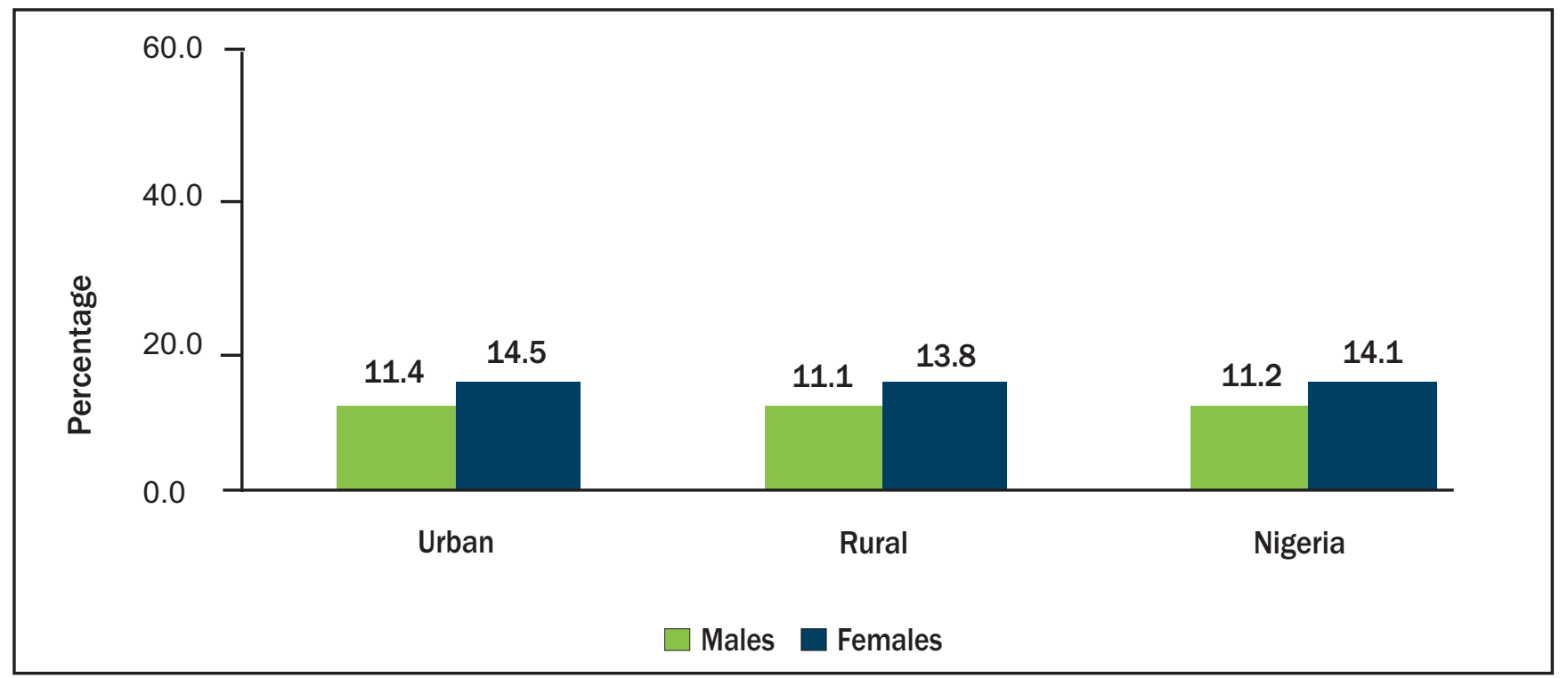

Data source: DHS 2008

\section{Multiple Sexual Partnerships}

Engagement in multiple sexual partnerships by sexually active respondents aged 15-24 is captured by the data presented in Figure 5. In line with societal gender norms, self-reporting of multiple sexual partnerships is relatively low among sexually active females (2.0-2.3\%) and relatively high among sexually active males (14.5-17.9\%). Self-reporting of multiple sexual partnerships decreases slightly with age for females and increases slightly with age for males. 
Young men's higher reporting of multiple sexual partnerships may be due to peer/societal pressure to demonstrate masculinity through sexual experience or prowess. ${ }^{20}$

FIGURE 4: AMONG RESPONDENTS WHO WERE SEXUALLY ACTIVE IN THE PAST 12 IMONTHS, PERCENTAGE REPORTING HAVING MULTIPLE SEXUAL PARTNERS BY AGE AND SEX

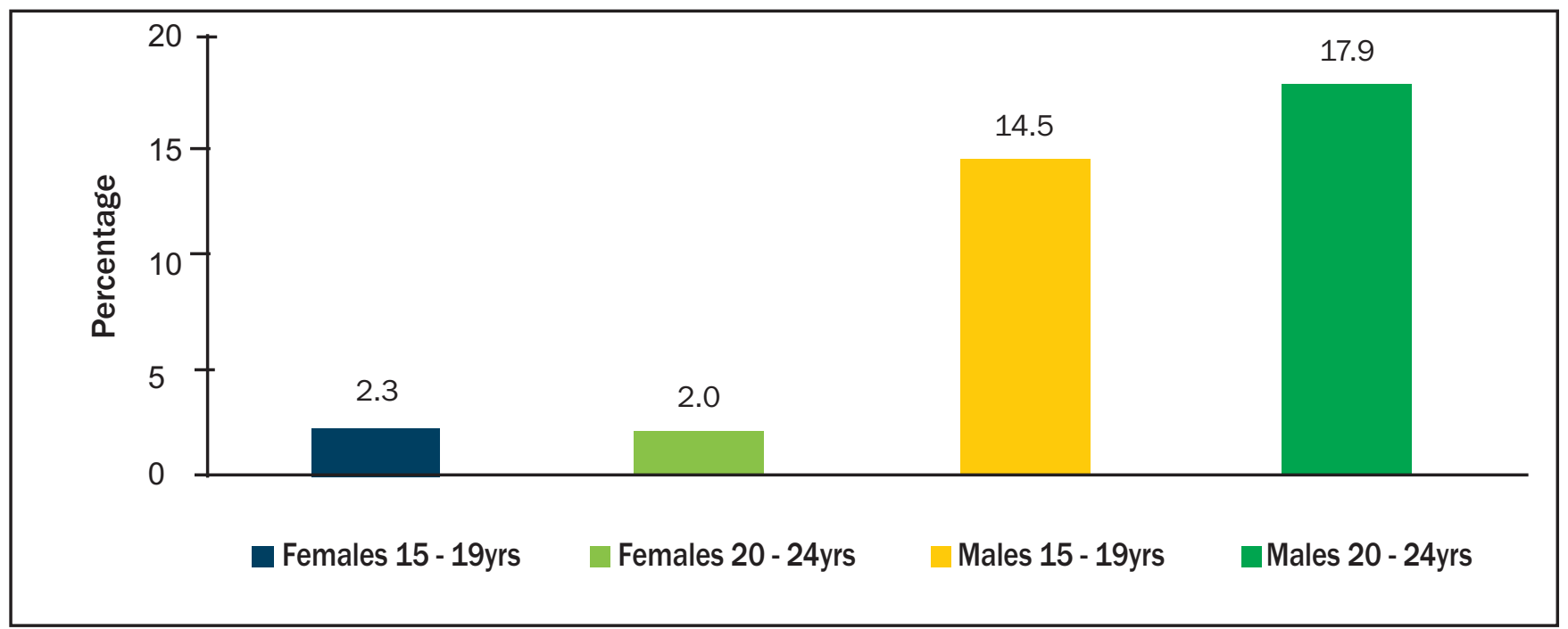

Data source: DHS 2008

\section{Sexual Health-seeking Behaviors}

\section{Condom Use}

Figure 5 reveals that levels of condom use at last sex among young people with multiple sexual partners varied from as low as 24.8 percent among female youth aged 15-19 to 61.3 percent among male youth of the same age group. Among young people who endorsed having multiple sexual partners, a greater proportion of young men than young women reported using condoms at last sex.

FIGURE 5: AMONG RESPONDENTS WITH MULTIPLE SEXUAL PARTNERS IN THE PAST 12 MONTHS, PERCENTAGE REPORTING CONDOM USE AT LAST SEX, BY AGE AND SEX

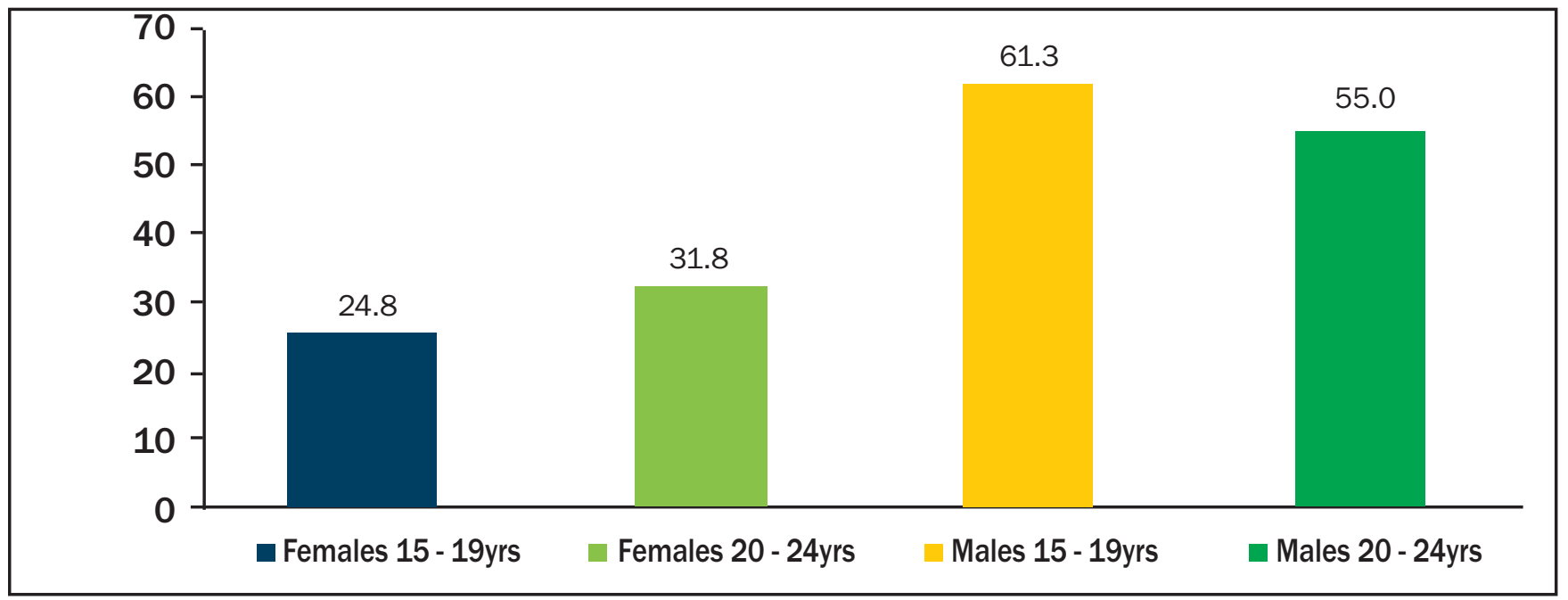

Data source: DHS 2008 
According to the figures presented in Table 1, condom use during last sex with multiple partners seemed to be relatively higher among young men than women. Also, lower levels of condom use were reported among rural male and female youth relative to their urban male and female peers respectively.

Reasons given by Nigerian youth for nonuse of condoms with sexual partners were shyness, fear of implying a lack of trust in their sexual partner, and concern about their reputation in the eyes of their partners, parents, or society. ${ }^{21,22}$ Lack of knowledge on correct use of condoms is also another possibility as revealed by a study conducted by Lawoyin among 18-30 year old women in Ibadan and Lagos. Only 35.3\% of the young women surveyed knew how to use a condom correctly. ${ }^{23}$

The low level of condom use among Nigerian youth is particularly worrisome given the relatively high levels of high-risk sexual behavior. Increased condom messaging and distribution, and the inclusion of condom/sexual negotiation skills in youth sexuality education/HIV prevention programs, are essential.

TABLE 1 : PERCENTAGE OF RESPONDENTS AGED 15-24 WHO USED A CONDOM AT LAST SEX AMONG THOSE WITH MULTIPLE PARTNERS IN THE PAST 12 MONTHS ACCORDING TO AGE AND SEX

\begin{tabular}{lll}
\hline & Males & Females \\
\hline Nigeria & 56.4 & 29.0 \\
Urban & 63.9 & 31.5 \\
Rural & 47.4 & 14.7 \\
\hline
\end{tabular}

Data source: DHS 2008

\section{Uptake of HIV testing}

Figure 6 shows that uptake of HIV testing among young people in Nigeria remains relatively low (ranging from 3.8-14.7 percent). Generally, the proportions of young women and men that reported ever seeking and receiving HIV-test results were roughly equal. Among the young people of both sexes and age groups (15-19 and 20-24), young women aged 20-24 reported the highest rate of obtaining an HIV test and receiving the results (14.7 percent) while young males aged 1519 reported the lowest rate of obtaining an HIV test and receiving the results (3.8 percent).

FIGURE 6 : PERCENTAGE OF RESPONDENTS REPORTING EVER BEING TESTED FOR HIV AND HAVING RECEIVED THE RESULTS, BY AGE AND SEX

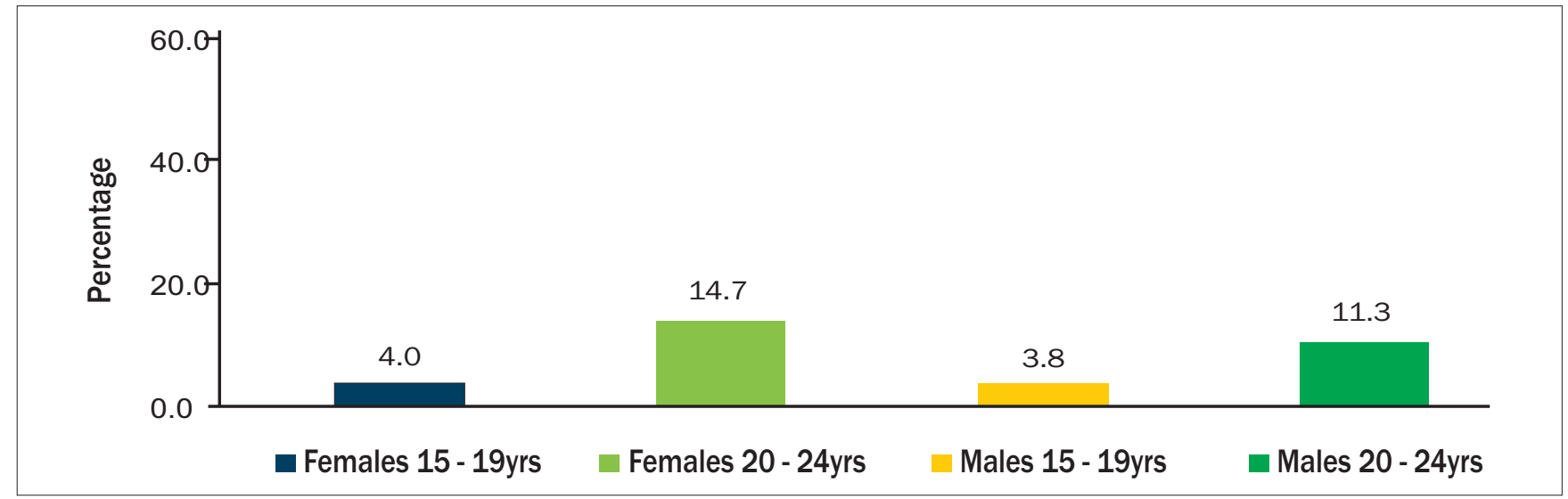

Data source: DHS 2008 
There is a clear disparity in HIV testing in terms of residence. More youth residing in urban areas reported ever seeking and ever obtaining HIV-test results than did their rural counterparts (Male: 15.5 percent vs. 9.4 percent; Female: 13.9 percent vs. 6.6 percent respectively). Factors that may contribute to the low uptake of voluntary counseling and testing (VCT) among youth are low awareness of VCT and places where VCT services are offered, low HIV risk perception,concerns about confidentiality, actual or perceived cost of VCT, fear of being positive, and stigmatization. ${ }^{24,25}$ The slight disparity between males and females with regard to uptake of VCT may be because pregnancy affords young women access to maternal/child services such as antenatal care, where VCT is one of several services provided. An additional factor may be men's poorer health-seeking behavior that results from gender norms that feminize illness and the seeking of formal medical care. ${ }^{26}$ Given the higher levels of self-reported high-risk behavior among young men, it is important for HIV prevention programmers to target interventions, especially VCT services, toward men, and to explore ways to increase male uptake of HIV services in general. Decreased access to VCT services and lower HIV knowledge in rural areas may be the reason for the urban-rural differences observed in VCT uptake. This highlights a need for program managers and policymakers to scale up and increase the geographic coverage of HIV services in Nigeria.

\section{Comprehensive HIV Knowledge}

HIV awareness was high in Nigeria, with more than 80 percent of youth reporting that they have ever heard of HIV. However, less than 35 percent of youth had comprehensive knowledge of HIV/AIDS according to a composite of the five UNGASS indicators for HIV knowledge (Figure 7). Generally, more young men demonstrated comprehensive knowledge of HIV than young women (32.6 percent vs. 22.2 percent) and between the age groups, higher proportions of youth aged 20-24 years of both sexes (Male, 37.2 percent and Female, 24.8 percent) demonstrated comprehensive knowledge than youth aged 15-19 years of both sexes (Male, 28.2 percent and Female, 19.7 percent). Also, more urban (Male, 39.7 percent and Female, 29.8 percent) than rural (Male, 28.2 percent and Female, 17.9 percent) youth had comprehensive knowledge of HIV (not shown).

FIGURE 7 : PERCENTAGE OF RESPONDENTS REPORTING CORRECT ANSWERS ON ALL FIVE INDICATORS OF HIV KNOWLEDGE, BY AGE AND SEX

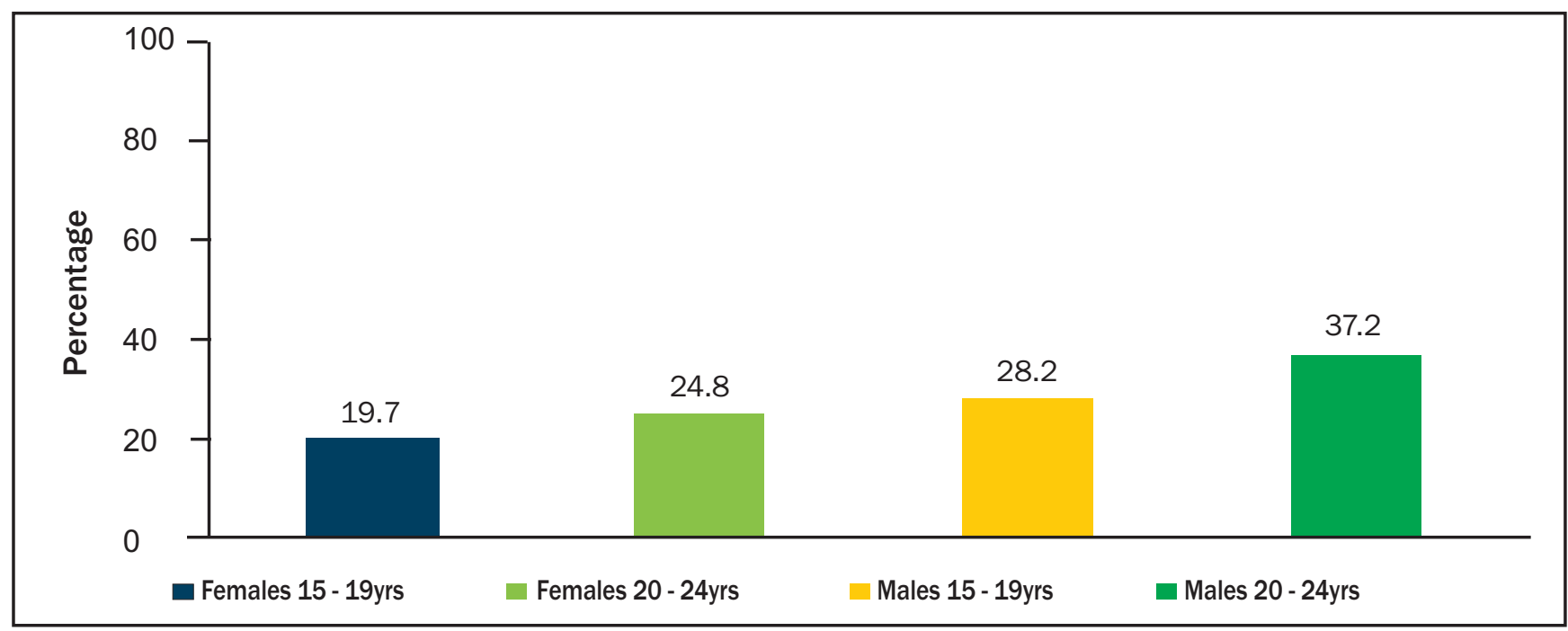

Data source: DHS 2008 


\section{Stigma and Discrimination}

According to UNAIDS, ${ }^{27}$ HIV/AIDS-related stigma can be described as a "process of devaluation" of people either living with or associated with HIV/AIDS, whereas discrimination follows stigma and is the unfair and unjust treatment of an individual based on his or her real or perceived HIV status. Stigma and discrimination breach fundamental human rights and can occur at a number of different levels, including economic, institutional, political, psychological, and social levels. A number of indicators have been used to measure stigma and discrimination that aim to identify an individual's level of stigma and discrimination, and their knowledge of the occurrence of stigma and discrimination. Stigma and discrimination play an enormous role in facilitating the spread of HIV by weakening prevention efforts, because fear of stigma and discrimination are the main reasons individuals refuse to be tested, disclose their sero-status, or take antiretroviral drugs.

FIGURE 8 : PERCENTAGE OF RESPONDENTS THAT WOULD NOT KEEP SECRET THE HIV-POSITIVE STATUS OF A FAMILY MEMBER, BY AGE AND SEX

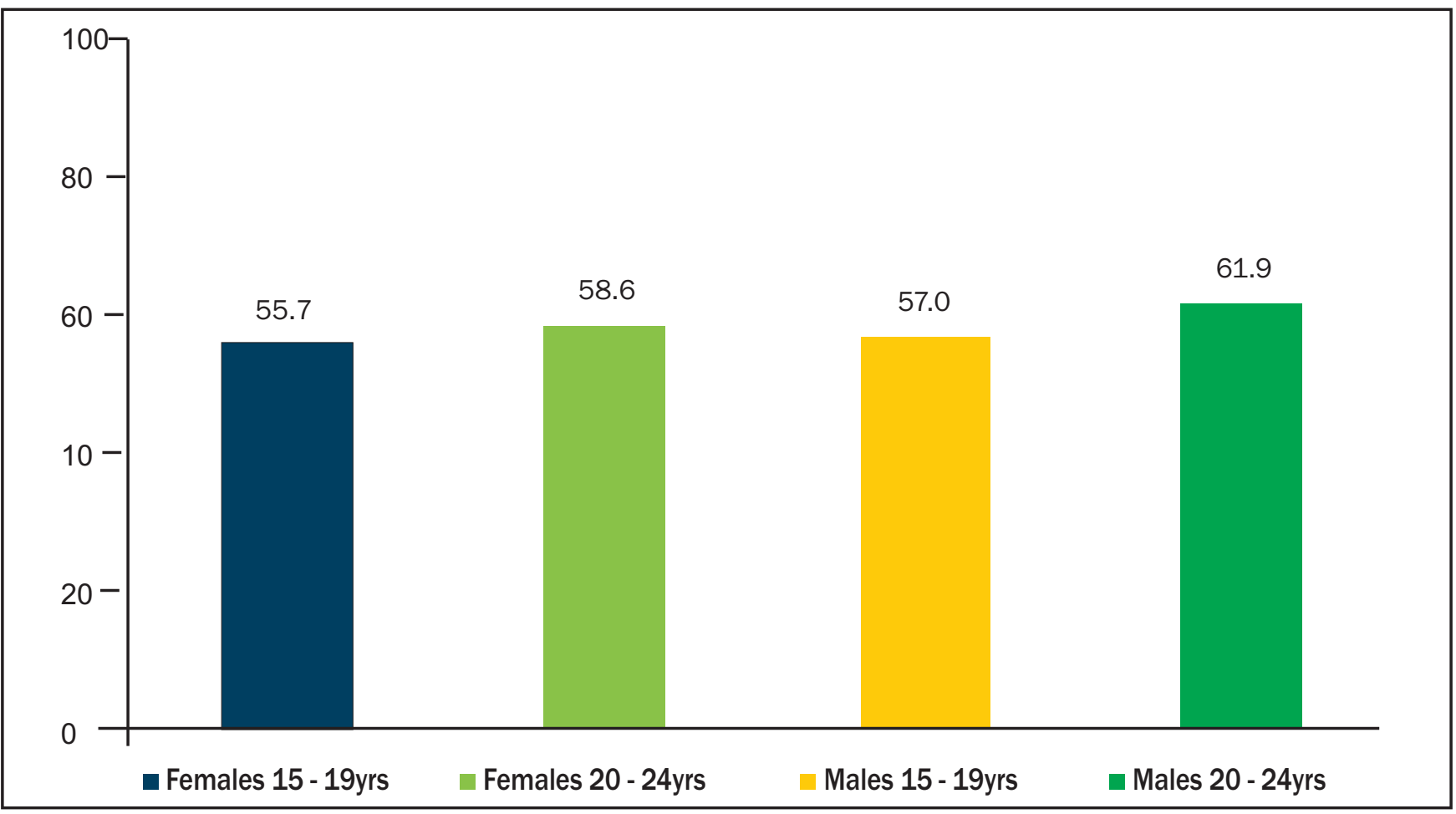

Data source: DHS 2008

Overall, relatively high proportions of young people (>50 percent) reported that they they would not want to keep secret the HIV-positive status of a family member (Figure 8). For both male

1"Comprehensive knowledge" refers to knowing that consistent use of condoms during sexual intercourse and that having just one HIV-negative, faithful partner can reduce the chances of becoming infected with HIV; knowing that a healthy-looking person can have HIV; and rejecting the two most common local misconceptions about HIV transmission and prevention. 
and female youth, relatively higher proportions of youth aged 20-24 years than youth aged 15-19 years would not want to keep secret the HIV-positive status of a family member. More rural (Female, 59.8\% and Male, 61.3\%) than urban (Female, 53.1\% and Male, 56.6\%) youth would not keep secret the HIV-positive status of a family member (not shown).

\section{FACTORS IN THE SEXUAL-RISK AND HEALTH-SEEKING BEHAVIORS OF YOUTH}

\section{Risky Sexual Behaviors}

The logistic regression analysis (Table 2) shows that females aged 15-24 were significantly more likely (RRR: 1.276) to have had sex on or before age 15 than males of the same age group. However, possession of any form of primary (RRR: 0.562), secondary (RRR: 0.514) or higher (RRR: 0.204) education was significantly associated with much reduced likelihood of early sexual debut relative to respondents with no formal education. A broadly similar inverse correlation also existed between household wealth status of youth and early sexual debut. On the other hand, being currently married (RRR: 5.222) and formerly married (RRR: 2.421) was significantly more predictive of having had sex on or before age 15 relative to being never married.

\section{TABLE 2: RELATIVE RISK RATIOS FROM LOGISTICS REGRESSION ANALYSIS OF PREDICTORS OF SEXUAL DEBUT ON OR BEFORE AGE 15 IN NIGERIA}

\begin{tabular}{lll}
\hline Characteristics & Relative risk ratio (RRR) & Standard error (se) \\
\hline Gender (Ref is Male) & $1.276 * * *$ & 0.098 \\
Female & & 0.046 \\
Residence (Ref is Rural) & $1.177 * * *$ & 0.039 \\
Urban & \\
Education (Ref is No education) & $0.562 * * *$ & 0.035 \\
Any primary & $0.514 * * *$ & 0.035 \\
Any secondary & $0.204 * * *$ & 0.348 \\
Any higher & & 0.286 \\
Marital status (Ref is Never married) & $5.222 * * *$ & $2.421 * * *$ \\
Currently married & & $0.849 * * *$ \\
Separated, divorced, or widowed & $0.567 * * *$ & 0.069 \\
Wealth (Ref is Wealth quintile 1) & & 0.023 \\
Wealth quintile 4 & & \\
Wealth quintile 5 & & \\
\hline
\end{tabular}

$* * *$ Significant at $p<0.01, * *$ Significant at $p<0.05$. Ref $=$ Reference category 
For current sexual activity among never-married youth aged 15-24 in Nigeria (Table 3), being aged 20-24 (compared to 15-19) was significantly associated with this behavior (RRR: 1.18) the same as with being currently working (RRR: 1.533) relative to "not working". By contrast, being female was associated with less likelihood of being sexually active among never-married youth. Household wealth status was shown to be significantly associated with current sexual activity among nevermarried youth; never-married youth from poor (wealth quintile 2) households are seen to have lower likelihood to be sexually active than their counterparts from the poorest (wealth quintile 1) households. Level of education was also significantly associated with likelihood of current sexual activity with those with any higher education being 5 times more likely to be currently sexually active than their peers with no education (Any primary - RRR: 1.79; Any secondary - RRR: 3.76; Any higher - RRR: 5.40).

\section{TABLE 3: RELATIVE RISK RATIOS FROM LOGISTICS REGRESSION ANALYSIS OF PREDICTORS OF CURRENT SEXUAL ACTIVITY AMONG NEVER-MARRIED YOUTH AGED 15-24 IN NIGERIA}

\begin{tabular}{lll}
\hline Characteristics & Relative risk ratio (RRR) & Standard error (se) \\
\hline Age (Ref is 15-19 years) & $1.180 * * *$ & 0.014 \\
$20-24$ years & $0.524 * * *$ & 0.040 \\
Gender (Ref is Male) & \\
Female & $1.794 * * *$ & 0.219 \\
Education (Ref is No education) & $3.761 * * *$ & 0.427 \\
Any primary & $5.399 * * *$ & 0.846 \\
Any secondary & & 0.100 \\
Any higher & & $1.533 * * *$ \\
Occupation (Ref is Not working) & & 0.093 \\
Currently working & & $0.765 * * *$ \\
Wealth (Ref is Wealth quintile 1) & & \\
Wealth quintile 2 & &
\end{tabular}

$* * *$ Significant at $p<0.01, * *$ Significant at $p<0.05$. Ref $=$ Reference category

\section{Condom use during last sex among those with multiple partners}

The regression estimates presented in Table 4 shows that in Nigeria, female youth (RRR: 0.558) involved in multiple sexual partnerships were significantly less likely to report using condoms during their last sexual intercourse than their male counterparts. This pattern may be attributable to young women's relatively weaker bargaining power during sex, either due to their association of condoms with infidelity, or being offered more money or material goods when engaged in inter-generational sex. Education and household wealth status, on the other hand, showed very strong positive association with condom use by youth with multiple sexual partners. Youth with any form of secondary and higher education were respectively about 7 and 10 times more likely to report using condoms during their last sexual intercourse than youth with no formal education. Also, youth from the rich (wealth quintile 4) and the richest (wealth quintile 5) households were respectively about 3 and 4 
times more likely to report using condoms during their last sexual intercourse than youth from poorest household (wealth quintile 1).

\section{TABLE 4: RELATIVE RISK RATIOS FROM LOGISTICS REGRESSION ANALYSIS OF PREDICTORS OF CONDOM USE DURING LAST SEX AMONG SEXUALLY ACTIVE YOUTH WHO HAD MULTIPLE PARTNERS IN THE PAST 12 MONTHS IN NIGERIA}

\begin{tabular}{|c|c|c|}
\hline Characteristics & Relative risk ratio (RRR) & Standard error (se) \\
\hline \multicolumn{3}{|l|}{ Age (Ref is $15-19$ years) } \\
\hline $20-24$ years & $1.120 * * *$ & 0.033 \\
\hline \multicolumn{3}{|l|}{ Gender (Ref is Male) } \\
\hline Female & $0.558 * * *$ & 0.069 \\
\hline \multicolumn{3}{|l|}{ Education (Ref is No education) } \\
\hline Any primary & $3.385 * * *$ & 0.966 \\
\hline Any secondary & $7.252 * * *$ & 1.901 \\
\hline Any higher & $9.869 * * *$ & 3.332 \\
\hline \multicolumn{3}{|l|}{ Marital status (Ref is Never married) } \\
\hline Currently married & $0.111 * * *$ & 0.034 \\
\hline Separated, divorced, or widowed & $0.183 * * *$ & 0.049 \\
\hline \multicolumn{3}{|l|}{ Residence (Ref is Rural) } \\
\hline Urban & $1.223 * * *$ & 0.095 \\
\hline \multicolumn{3}{|l|}{ Occupation (Ref is Not working) } \\
\hline Currently working & $1.429 * * *$ & 0.187 \\
\hline \multicolumn{3}{|l|}{ Wealth (Ref is Wealth quintile 1) } \\
\hline Wealth quintile 2 & $1.994 * * *$ & 0.591 \\
\hline Wealth quintile 3 & $2.200 * * *$ & 0.716 \\
\hline Wealth quintile 4 & $3.009 * * *$ & 1.168 \\
\hline Wealth quintile 5 & $3.632 * * *$ & 0.014 \\
\hline
\end{tabular}

$* * *$ Significant at $\mathrm{p}<0.01, * *$ Significant at $\mathrm{p}<0.05$. Ref=Reference category

\section{Factors Associated with Comprehensive Knowledge of HIV}

As shown in Table 5, factors that were significantly predictive of comprehensive knowledge of HIV among young people in Nigeria were age, gender, education and household wealth index. For instance, youth with any form of primary, secondary and higher education were respectively 1.5, 2.6 and 3.8 times more likely to display comprehensive knowledge of HIV than their peers with no formal education net of the effect of the other variables in the regression model (age, gender, occupational status, household wealth status, and rural-urban residence). Similarly, though of smaller magnitude, 15-24 years-olds resident in the richest households (wealth quintile 5) were 2.1 times more likely to report comprehensive knowledge of HIV than their peers from the poorest households. 
It is also noteworthy that older youth (RRR: 1.079) were slightly more likely to display comprehensive knowledge of HIV than youth aged 15-19 years. Female youth, on the other hand, were less likely to report comprehensive knowledge of HIV than their male counterparts. Overall, these patterns suggest the need to target HIV prevention education efforts towards socially disadvantaged youth in Nigeria as knowledge influences behaviors, beliefs and perceptions.

\section{TABLE 5: RELATIVE RISK RATIOS FROM LOGISTICS REGRESSION ANALYSIS OF PREDICTORS OF COMPREHENSIVE KNOWLEDGE OF HIV AMONG RESPONDENTS}

\begin{tabular}{lll}
\hline Characteristics & Relative risk ratio (RRR) & Standard error (se) \\
\hline Age (Ref is 15-19 years) & $1.079 * * *$ & 0.009 \\
20-24 years & $0.694 * * *$ & 0.041 \\
Gender (Ref is Male) & \\
Female & $1.486 * * *$ & 0.136 \\
Education (Ref is No education) & $2.554 * * *$ & 0.228 \\
Any primary & $3.801 * * *$ & 0.466 \\
Any secondary & & 0.110 \\
Any higher & & 0.142 \\
Wealth (Ref is Wealth quintile 1) & $1.413 * * *$ & 1.179 \\
Wealth quintile 2 & $1.627 * * *$ & $1.861 * * *$ \\
Wealth quintile 3 & $2.139 * * *$ & 0.231 \\
Wealth quintile 4 & & \\
Wealth quintile 5 & &
\end{tabular}

$* * *$ Significant at $p<0.01, * *$ Significant at $p<0.05$. Ref $=$ Reference category

\section{QUALITATIVE INQUIRIES ON HIV YOUTH-FOCUSED RESPONSES AT THE INDIVIDUAL, INSTITUTIONAL, AND POLICY LEVELS}

\section{Overview}

Youth-focused responses at the individual, institutional, and policy levels are currently insufficient to tackle the HIV-related vulnerabilities of young people. At the individual level, Nigerian youth lack access to appropriate SRH information and confidential, low-cost, and stigma-free SRH services. Institutional responses are hampered by sociocultural sensitivities to youth premarital sexual activity, inadequate provision of sexuality education, and limited geographic and target population reach of current youth-focused programming. There continue to be few youth-specific policy provisions, which are hindered by weak political commitment and inadequate resourcing for implementation.

\section{Individual-Level Concerns and Responses}

Health-seeking behaviour is a very important determinant of the health status of people. It 
centres on the feelings and attitudes of youth about where they can seek sexual and reproductive health care. Many factors moderate health-seeking behaviour among youth. Findings show that because of the social and cultural environment surrounding the socialisation of young people most young people find it difficult to present themselves for sexual and reproductive health care.

\begin{abstract}
"Because there are so many things basically young people need especially their sexual health needs, there are so many things attached to it. But these health care providers, they don't want to know that. Once they see a young girl of 15 or 16 years going to health centre to get condom, they will like, the way they will look at her, that it's not for her, she is so wayward and so they don't help matters by their attitude" (IDI, MSM).
\end{abstract}

In addition, young people have a care-free attitude towards their health status. As noted by a respondent, the culture to seek health care among young people is lacking, even when they have an opportunity to utilise free health care services. According to him:

\begin{abstract}
"How many times have you said "Oh, I am not feeling well, let me go and see my doctor and do a general check-up?" Even when we say there's free HIV test, how many youth would you see on a line to get that service? In fact if they would ever do the test, they prefer to go without the counselling. They won't go. They will just go inside, take the blood and do it. So, you know, general health seeking behaviours it's not just right, ok" (KII, Staff of HIV focused NGO)
\end{abstract}

A female respondent observed that most young people do not seek sexual and reproductive health care until the "the virus has eaten them up." In her view, there are delays in accessing treatment or counselling that aggravate the effects of infection.

\title{
Macrosocial Service-Delivery-Level/Institutional Responses
}

Institutional responses to HIV and SRH education and appropriate access to youth-friendly services, especially for the most vulnerable groups of youth, continue to fall short of the needs and expectations of young people. This is true on both the community and national level.

Access to necessary HIV and SRH information is still being denied to young people contributing to their vulnerabilities. The failures of institutional responses in Nigeria in this regard can be tied to the broader issue of denial and lack of openness about youth sexuality. According to most respondents, there is a general acknowledgement in society that young people are sexually active, however sex remains taboo and is barely discussed in most homes and schools. Some respondents mentionedthat society still holds the view that if sex education is provided to young people, then they will behave "immorally."

\footnotetext{
"Because everyone thinks that when you talk about sex, and if we go into the depth of it, we are going to get the children corrupt. So they don't want to go too far." (FGD male and female youth)
} 
Because of these taboos, most parents fail to initiate discussions with their children about sex. Parents and other adult members of society were said to be uncomfortable discussing issues of sexuality with young people. A lot of parents seem to find talking about sex "embarrassing" or amounting to "bad manners," hence many ignore the subject or shy away from it.

\begin{abstract}
"There are some families that the parents are enlightened quite all right but because of some socio-cultural norms and old value, it is forbidden for them to talk about sex to mention their private parts, the names...." (FGD, male youth)
\end{abstract}

In parts of Nigeria, adult attitudes are strongly rooted in cultural and religious values. Hence, adults find it difficult to accept that young people are sexually active.

\title{
"For example you are watching a romantic film, and then they show something. Your parent just walks in, they will just off the TV... (laughter) it's not only our parents, you are watching Superscreen and they show that part, they will just cut it off..." (FGD, male and female youth)
}

Where sexuality education is provided, the information is inadequate. Some participants questioned the scope of information provided. Participants stated that in primary and secondary schools, sexuality education only covers a narrow set of topics mostly limited to abstinence. It appears that topics on condom use, family planning, and HIV testing and counseling are not universally taught, yet participants viewed them as important in taking preventative action.

\footnotetext{
"If you go to school, you will see the teachers are not ready to go to that level. Don't let us go to private school, let's use government school. That's where the bulk of students are.

Teachers when they want to teach it (sexuality education), the student will start using all sort of absurd words and the teacher will just end it there and be like ... "is it these ones I want to teach?" (FGD male and female youth)
}

\footnotetext{
"Because in my school, all we do is the reproductive organs and I have not even seen any school that has gone that wild... [angrily] telling a school student how to use condom, how to wear condom..." (FGD, male and female youth)
}

Participants also felt that the reach of youth-focused programs was limited and some vulnerable groups of youth were not adequately involved in current youth-focused programming. The perception among participants was that there were few programs targeting out-of-school youth. Therefore, most out-of-school youth mainly obtained SRH and HIV information through community channels such as community outreach activities, peer education, and from attending seminars. However, participants felt that out-of-school youth were not as well-informed as their in-school counterparts regarding SRH and HIV. 


\begin{abstract}
"Yes, for me it's (sexuality education) just for the students...you will have access, information and all that...because I think most of them on the street, don't really know anything about it, they find it very difficult to talk about. If you kind of mention condom, in their presence, they feel shy...so they don't really have...like 60 percent are not aware." (FGD, male and female youth)
\end{abstract}

Participants mentioned that they were aware of existing programs for orphaned children. Such programs were said to offer a range of services including ARVs, treatment and care, food, and financial and material support. Most of these services are supported by NGOs. Because of pervasive stigma and discrimination, not all respondents were in agreement that orphans receive the necessary support they require.

"There is no support for orphans, girls and boys infected by HIV/AIDS, because of the stigma and discrimination. People withdraw their children/wards from the school." (FGD, youth)

No mention was made of programs targeting street youth besides the laws and policies on child labor, trafficking, and sex work that seemed familiar to respondents.

“There is, like the Federal Government they've impose this child labor and prostitution, that is, how will I put it, prosecution against child labor and prostitution in Nigeria. But I don't know how effective it is...instead of pursuing prostitutes they're been sent to, and those street children, underage children, orphanage children who are being sent into the street for hawking instead of them tackling those issues. They left those issues and prostitution, and what they are pursuing is how to chase one poverty woman trying to make up his life by the roadside." (FGD, female youth)

It was clear from the qualitative inquiries that HIV-positive Nigerian youth continued to live in fear and secrecy and faced stigma and discrimination from family, friends and peers.

\footnotetext{
"If they know that you are a person living with AIDS, your relatives, all of them will run away from you, even outsiders will stigmatize you like when I was under care, all my relatives, were not there because of my status, that is even why I am yet to marry." (FGD female PLHA)

"Like they say, some people have it, but would rather stay in their house than coming out, because when they come out, even among their relatives, you will see them running away from the person. And even if the person gives a child something to eat, they will collect it and throw it away." (FGD female youth)
}

Most of the youth easily identified various HIV and SRH services and where such services could be obtained, regardless of whether they had previously utilized the services. HCT services were said to be widely available by youth across the study sites. Both private and public facilities were identified as offering these services. SRH services were also reported 
to be available among a number of service providers. The same applied to PMTCT, HIV care and support services, ARV and family planning services.

Although it was acknowledged that many government facilities provided similar services, some respondents were reluctant to seek services from those facilities because of fear of confidentiality breaches and unnecessary bureaucracy; instead they opted for NGO-based services or private facilities.

\footnotetext{
“Those providers at government owned clinics are always reluctant, and it's always crowded. They even ignore some patients that are already HIV positive and be wandering aimlessly. They discriminate and stigmatise. Things that are not their concerns, that's what they will be doing. Even doctors will not help.....So I don't like government-owned clinic from the onset" (IDI, female married adolescent).
}

\title{
Policy Responses
}

A few youth-specific policy provisions exist and they are generally not followed through with adequate resourcing (funding, personnel, infrastructure, and supplies) of programs and services, especially for rural and poor urban youth, out-of-school youth, and young MARPs.

Interviews with key stakeholders and program managers reveal that a few high-quality SRH and HIV policies exist for youth. According to the respondents, the concern is more on commitment in implementing the policies. Many stakeholders mentioned that there is laxity in implementation and misappropriation of funds, which undermines implementation of youth programs. Some key respondents made the following observations:

\begin{abstract}
“Em let's let's start by saying yes they are there, they are beautiful documents, they are functional but it is at the level of implementation that you have this gap is either someone is not looking at these documents and applying it to the needs of young persons or there is somebody who understood the needs of the young person but does not know what the provision is in the policy. So that gap is there but if you look at the document as it is like the national youth policy, even the HIV policy, the NSP the... the issue of young person including even the issue of disability you know it is in some of these documents they are there but there is this inertia of you know, maybe people don'tknow what to do or they just feel there isn't too much direction on how to go about implementing them." (KII, Staff of UN Agency)
\end{abstract}

"Everybody speaks to the importance of young people, but the truth of the matter is, how much of that money gets allocated to the issues that would make a difference in the epidemic amongst young people? The money is not appropriately allocated." (KII, Head of youth focused NGO)

Although, the national HIV/AIDS policy recognizes the need to program for MARPs, there is no specific focus on young MARPs and as discussed previously the legal and sociocultural environment remains disenabling for these populations. Criminalization of same-sex practice was viewed as a barrier in providing services among MSM. 
"The recent anti-gay marriage policy recently passed..... (on barriers faced by youth when accessing SRH services). The aspect of 10years imprisonment for people associated, working, or identifying with them. MSM practice is also prevalent among the youth and they must be reached with SRH/HIV information" (KII, Head of SRH focused NGO).

"We certainly are very, very concerned, when we see the suggestion that legislation's going to be brought in, which is going to be very, very punitive of these groups and it is unfortunately likely to impact quite seriously on young gay men...that's why I think this is something that needs to be highlighted......Any suggestion that there should be legal things to strengthen the criminalization of homosexual acts, we think it's going to make the situation much, much worse. We know this is on the table in the parliament.... And then you're hearing in the news that they even want to make the laws even stronger that anybody that tries to approach them or even help them to approach themcould be put in jail.... I mean.... that enough is enough to drive them further underground and to prevent people that have the ability to provide the services to stay away from doing that. So, it's just going to make it worse. I mean.....it's not like it's good now so criminalizing it further will make it even worse" (KII, World Bank Staff).

Other categories of youth like rural youth, married adolescents, incarcerated youth, almajiris, disabled youth, and young PLHA were seen as less likely to be reached by existing programs and services.

\footnotetext{
"Young people with disabilities.....they are considered asexual or non-vulnerable. Young people in prisons....they are considered as criminals that have no sexual rights. Young people in rural and hard to reach areas, they are considered uncivilized so not vulnerable. Street children, the "Almajiris" and the single mothers" (KII, Head of SRH focused NGO).

"In fact there are a lot of youths that may not be reached, except you go all out to reach them, like the mentally or physically challenged, like even some married adolescents, like those that don't come out of their houses, you have to deliberately look for ways to go and reach them. Like may be young people that may be incarcerated, they may never be reached" (KII, Head of youth focused NGO).
}

Lack of political will and subscription to traditional cultural norms were also viewed as impediments to implementation of youth-friendly HIV and SRH laws and policies.

"The mental model of the policymakers, that young people are not sexually active, that they don't need education and the definition of youths which is misleading is also a problem.

Apart from that, they don't see young people as an issue for them. For them it is non-existent, it's like ok, it's the western world that are trying to bring all these ideas to their society, that it's not what is obtained in their society" (KII, Head of youth-focused NGO). 
In general, the external donor community was perceived to be committed in funding youth programs, but the problem of a donor-driven agenda as a possible detriment to the efficacy of the national HIV response was also highlighted.

\begin{abstract}
"The donor community is trying because most of the funding going into HIV programming among youth is from them though some of the donors also have their own agenda." (KII Head of $\mathrm{SRH}$ focused NGO)

"The donor....unfortunately the donor, they always have their own direction or focus or what they want to achieve. This always serves their own plan, serves their own policy." (KII, senior M\&E manager at NGO)
\end{abstract}

\title{
YOUTH INVOLVEMENT IN PROGRAM IMPLEMENTATION AND SERVICE DELIVERY
}

It was clear from the narratives that participation by young people in different stages of SRH and HIV programming (design, implementation, and evaluation) is low and rarely goes beyond planning-stage consultations and provision of peer education/counseling.

"Passing the information. That's the only aspect they would be involved in" (IDI, female out of school youth)

Overall, the lack of youth involvement is a major concern to young people, who feel that this is a serious gap in the system.

"I will first of all tell them to carry the youths along in any anything they are trying to do any seminar, programs they should inform the youths. They should let them be informed. They should do by all means create awareness letting youths be much more involved than letting adults. By doing that it will increase it" (IDI, out of school male youth).

"No, most times it not always young persons that is the issue...but since it's adults they always want to do things in their own best interest so it's always amongst the adult to do the budgeting, they do the activities" (IDI out of school female youth).

\section{KEY INSTITUTIONAL ACTORS IN THE RESPONSE TO YOUTH VULNERABILITY TO HIV/AIDS}

The qualitative inquiries conducted assisted the identification of key institutional stakeholders who work on youth HIV-related issues in Nigeria. 
TABLE 6: KEY INSTITUTIONAL ACTORS RESPONDING TO YOUTH VULNERABILITY TO HIV/AIDS

\begin{tabular}{|l|l|}
\hline & Findings \\
\hline Type of Organizations & Mostly NGOs/Donors \\
\hline Youth Populations Focused On & Predominantly focused on general population of youth. OVC is vulnerable group \\
& most commonly programmed for. Limited programming for sexual minorities \\
& $($ MSM), drug users, out-of-school youth, married adolescents.
\end{tabular}

Source: Inventory of youth-focused organizations

NGOs (local and international) dominate the lists of institutions thought to be most actively engaged in youth-centered HIV programs and services. Youth interviewed also see the NGO sector as operating independently without support from the government and perceived these organizations as being vibrant and more visible when it comes to implementation of SRH/HIV policies.

"The places I know are nongovernmental organizations getting involved. government themselves.... well we can say they are involved, but not in an open way, they still use people's information, for instance, I want to access HIV, and I come and get tested, and they find out that I'm positive, thereaction, I will not want to go there again, and I spread the news around that, that hospital is not good. So I think the real people who now take it upon themselves are the NGOs" (FGD male and female youth).

"I will give nongovernmental a 100 percent, because our own government do they care? They don't care. If you like pack all the HIV, they don't care. The only thing they care about is what is coming out of resources. That's the only thing government cares about. But our own personal health here, they don't care. In UK, they are trying to stop the virus, but here nothing" (FGD male and female youth).

This insight raises questions on the coverage, ownership, and sustainability of these services, because these organizations are wholly external-donor funded as voiced by key informants:

"The government across the three tiers has not been seen as doing much in terms of funding. There have been so much talk but with little action. However, it's worthy of note that in most of the states of the federation, the government is providing enablement for programme implementation. The main issue is that we should move away from donor driven intervention to nation led ones. Nigerian government should have budget lines and release the money for its intended use" (KII, Head of SRH focused NGO).

"Funding for HIV/AIDS in Nigeria is mainly from international donors. CSOs have no choice but to conform to donor-driven agendas, which may not necessarily solve immediate community needs." (KII, Nigeria) 
TABLE 7: PROPORTION OF HIV-FUNDING ALLOCATION IN NIGERIA FOR YOUTH INTERVENTIONS

\begin{tabular}{|l|l|l|}
\hline Government & International Donors & Private Sector \\
\hline Not a significant contributor. & Main source of funding for HIV. & Limited information on private - \\
& Donors mentioned include & sector contribution. \\
& DFID, Global Fund, PEPFAR, & \\
& World Bank, and Ford & \\
& Foundation. & \\
\hline
\end{tabular}

Source: KIls with policymakers and program managers 


\section{Conclusion and Recommendations}

\section{OVERVIEW OF KEY FINDINGS}

\section{Legal and Policy Issues in Youth Vulnerabilities to HIV and Sexual Health Challenges}

- Conflicting provisions under overlapping legal systems-customary, statutory/civil, and religious-engender violations regarding child marriage, age of consent, access to SRH information, etc.

- Non-domestication or incomplete domestication of key international and regional protocols, e.g., CEDAW and the Maputo Declaration.

- Non-provision for marital rape represents a double jeopardy for married adolescents as they face heightened risk of HIV infection by often being married to much older sexually experienced men who frequently force them to have sex -and restrictions on access to abortion services for female youth is the norm.

- Minimal laws and policies on AIDS-related stigma and discrimination and poor enforcement of existing provisions.

- Criminalization of sex work and same-sex relations acts as major barrier to efforts to address the HIV/SRH needs of young MARPs.

- National AIDS policies and strategic frameworks make few youth-specific and youthcentered provisions.

- Loud policy silence regarding very young adolescents and young MARPs (sex workers, IDUs, MSM, and other sexual minorities).

\section{Patterns in Risk Behaviors and HIV-Related Discrimination}

- Current sexual activity among never-married youth seems to be a function of age, gender, education, employment status and household wealth quintile; increased educational level, lower household wealth quintile, being aged 20-24 and being male were predictive of this outcome among six associated factors.

- Females aged 15-24 were significantly more likely to have had sex on or before age 15, less likely to report using condoms during their last sexual intercourse (among those with multiple sexual partners), and were less likely to report comprehensive knowledge of HIV than males of the same age group.

- Posession of any form of primary, secondary or higher education was significantly associated with much reduced likelihood of early sexual debut relative to respondents with no formal education. A broadly similar inverse correlation also existed between household wealth status of youth and early sexual debut.

- Education and household wealth status showed very strong positive association with condom use by youth with multiple sexual partners.

- Age, education and household wealth index were also significantly positively predictive of comprehensive knowledge of HIV among young people.

- Relatively high proportions of young people (>50 percent) reported that they would not want to keep secret the HIV-positive status of a family member 


\section{HIV Youth-Focused Responses at the Individual, Institutional, and Policy Levels}

- Youth sexual-health-seeking behavior as gauged by their level of comprehensive HIV knowledge (Female 15-19: 19.7\%; Females 20-24: 24.8\%; Males 15-19: 28.2\%; Males 2024: $37.2 \%$ ), use of condomsduring last sex for those with multiple sexual partners (Females: 29.0\%; Males: 56.4\%), and uptake of HCT services (Females 15-19: 4\%; Females 20-24: 14.7\%; Males 15-19: 3.8\%; Males 20-24: 11.3\%)is relatively low.

- Service provider issues (attitudes, competence, etc.) are cited by many young respondents as major barriers to access the very few available youth-friendly services.

- Youth experiences with existing HIV programs and services are mixed, although they are more negative among MSM, who generally feel discriminated against by care providers.

- The few youth-specific policy provisions are generally not followed through with adequate resourcing (funding, personnel, infrastructure, and supplies) of programs and services, especially for rural and poor urban youth, out-of-school youth, and young MARPs.

- Youth participation in policy development and program implementation rarely goes beyond planning-stage consultations and provision of peer education/counseling.

- Huge public-private (NGO) sector gaps exist in the provision of quality youth-friendly services.

\section{DISCUSSION AND IMPLICATIONS}

This study highlights salient gaps and deficiencies in HIV-prevention programming among youth in Nigeria. Nigerian youth continue to be a vulnerable group. Whereas it is imperative and a fundamental human right to provide quality education to all children and youth, it is also essential that they be provided with the skill-sets to better protect themselves during their budding sexuality. Furthermore, the imbalance between high-risk sex and condom use in high-risk sex raises concern for HIV prevention. This is a potent transmission bridge within youth and between youth and highrisk groups, thus perpetuating the HIV cycle between different sub-populations.

The relatively high levels of sexual activity among Nigerian youth demonstrate the need for educating young people regarding safer sexual practices. This young population should have access to SRH services and youth-focused sexuality education that goes beyond abstinence-only messages. Prevention programs aimed at delaying sexual debut are important in the Nigerian context and should focus on both boys and girls and take into account the roles of poverty and sexual coercion in determining the sexual experiences of young men and women. Efforts to raise the awareness of parents, policymakers, and communities about the health and human rights implications of early marriage and sexual coercion among girls continue to be important and should be strengthened, as should interventions focusing on the financial empowerment of youth.

Another salient finding from this study is the lack of significant engagement of youth in policymaking, implementation, and HIV-prevention programming. There is a large mismatch between what is developed for youth and what young people expect from the government. Also because of poor datause and dissemination at the policy level, key stakeholders responsible for 
formulating appropriate policies for youth lack the required evidence to design effective policies. This has multilevel impact, including advocating for necessary funding for youth-based programs. Health-care providers, who are supposed to give succor to youth, become hostile and provide a concomitant health-care environment that is not sensitive to the needs of young people who require SRH services. Youth complained of being accused and judged of being immoral and denied treatment, sometimes with verbal and physical insult. There is, thus, a need to sensitize all cadres of health staff to be youth-friendly. Furthermore, health-care settings should be open, accessible, and welcoming to youth. Having a health-care facility less than five minutes walking distance does not translate to accessibility because proximity does not guarantee that services will be delivered to those who need them.

Comprehensive knowledge of HIV remains poor and is even poorer among female youth. While this study did not evaluate any method of disseminating HIV knowledge, the low levels recorded raise cause for alarm. The health-belief model $^{28}$ is founded on the principle that there is a relationship between beliefs, attitudes, and behavior. Knowledge influences beliefs and perceptions and this fact has been key in HIV-prevention programs focusing on improving HIV knowledge. However, with reference to the UNAIDS business case for youth, ${ }^{29}$ where at least 80 percent of young people in and out of school are expected to have comprehensive HIV knowledge, the data show that a lot of work still needs to be done to achieve this target.

\section{RECOMMENDATIONS}

Based on the findings of this study, the following strategic actions are hereby recommended:

- Improving sexual-health-seeking behaviors, especially uptake of HCT and condom use by youth, through a combination of youth-empowering communication and poverty-reduction interventions is imperative.

- Evidence-based advocacy needs to be targeted at policymakers and donors to drive greater attention to the youth dimensions of the HIV epidemic, especially in relation to neglected but vulnerable categories of youth such as MSM, sex workers, married adolescents, and street children.

- Innovative operations research is called for to better understand how to increase the meaningful involvement of young people in the conception, planning, and implementation of SRH and HIV/AIDS policies and programs.

- Efforts to promote the mainstreaming of youth-friendly SRH and HIV services are required given the challenges of scaling up and sustaining the few model standalone services provided largely by NGOs.

- Systematic domestication and implementation of key international regional protocols to align with the Nigerian context needs to be advocated for strongly.

- Alignment of civil, religious, and customary laws to ensure laws and policies are not contradictory needs to be fully explored.

- The effective implementation of youth-specific laws and policies remains a challenge 
requiring multisectoral and multilevel actions, including increased funding.

- The National AIDS Control Agency (NACA) must live up to its oversight function in ensuring that young people are not neglected in national HIV policies and programs.

- Government needs to increase funding and demonstrate ownership and sustainability of youth-based HIV programs. 


\section{References}

1. National Population Commission Abuja: 2006 Population and Housing Census of the Federal Republic of Nigeria Priority Tables (Volume 1) 2009.

2. Federal Ministry of Health [Nigeria] (2013) National HIV/AIDS and Reproductive Health Survey, 2012 (NARHS Plus II 2012). Federal Ministry of Health Abuja, Nigeria.

3. National Agency for the Control of AIDS 2010. National Research Agenda on HIV/AIDS in Nigeria 2010-2015. Abuja, The Presidency.

4. The World Bank. 2008. The World Bank's Commitment to HIV/AIDS in Africa. Washington, DC: The World Bank.

5. United Nations Population Fund (UNFPA). Factsheet: Young People's Health and Development in Nigeria.

6. Joint United Nations Programme on HIV/AIDS (UNAIDS). 2010. Trends in HIV Prevalence and Sexual Behaviour among Young People aged 15-24 years in Countries most affected by HIV. Geneva: UNAIDS.

7. Sedlock 2000. "Reaching the youngest adolescents with reproductive health programs," In FOCUS Series. Washington DC: Focus on Young Adults.

8. QSR Nvivo 9 Software (International Pty 2007, Australia).

9. National Population Commission (NPC) [Nigeria] and ICF Macro. 2009. Nigeria Demographic and Health Survey 2008. Abuja, Nigeria; National Population Commission and ICF Macro.

10. US Department of State, Country Reports on Human Rights Practices 2009

11. Population Council. Child Marriage Briefing: Nigeria. 2005. New York: Population Council.

12. US Department of State, Country Reports on Human Rights Practices 2011

13. Social Institutions and Gender Index (SIGI). Gender equality and social institutions in Nigeria. OECD. Available at: http://genderindex.org/country/nigeria. Accessed 5 March, 2012

14. US Department of State, Country Reports on Human Rights Practices 2003

15. Joint United Nations Programme on HIV/AIDS (UNAIDS). 2002. “Sex Work and HIV/AIDS: Technical Update." Geneva: UNAIDS

16. Smith et al. 2009. "Men who have Sex with Men and HIV in sub-Saharan Africa," Lancet 374: 416-22

17. Federal Ministry of Health. Integrated Biological and Behavioral Surveillance Survey (IBBSS). Abuja, Nigeria: 2010.

18. National Agency for the Control of AIDS. 2009. National HIV/AIDS Policy Review Report. Abuja, The Presidency.

19. Harrison A., J. Cleland, E. Gouws, and J. Frohlich. 2005. "Early sexual debut among young men in rural South Africa: Heightened vulnerability to sexual risk," Sexually Transmitted Infections 81: 259-261.

20. Varga, C.A. 2001. "The forgotten fifty percent: A review of sexual and reproductive health research and programs focused on boys and young men in sub-Saharan Africa," African Journal of Reproductive Health 5(3): 175-195.

21. Adedimeji, A.A., F.O. Omololu, O. Odutolu. 2007. "HIV Risk Perception and Constraints to 
Protective Behaviour among Young Slum Dwellers in Ibadan, Nigeria," Journal of Health, Population, and Nutrition 25(2): 146-157

22. Owolabi, A., A. Onayade, I. Ogunsola, et al. 2005. "Sexual behaviour of secondary school adolescents in Ilesa, Nigeria: Implications for the spread of STIs including HIV/AIDS," Journal of Obstetrics and Gynaecology 25(2): 174-178.

23. Lawoyin OOC. 2007. Findings from an HIV/AIDS programme for young women in two Nigerian cities: a short report. Afr J Reprod Health; 11(2):99-106.

24. Yahaya, L.A., A.A.G. Jimoh, and O.R. Balogun. 2010. "Factors hindering acceptance of HIV/AIDS voluntary counselling and testing (VCT) among youths in Kwara State, Nigeria," Journal of AIDS and HIV Research 2(7): 138-143

25. Ikechebelu, I.J., G.O. Udigwe, N. Ikechebelu, and L.C. Imoh. 2006. "The knowledge, attitude and practice of voluntary counselling and testing (VCT) for HIV/AIDS among undergraduates in a polytechnic in southeast, Nigeria," Nigerian Journal of Medicine 15(3): 245-249

26. Myburgh, H. 2011. The clinic as a gendered space: Masculinities, health-seeking behavior, and HIV \&AIDS.

<http://www.consultancyafrica.com/index.php?option=com_content\&view=article\&id=760:t he-clinic-as-a-gendered-space-masculinities-health-seeking-behaviour-and-hiv-aaids\&catid=61: hiv-aids-discussion-papers\&ltemid=268>. Accessed August 2012.

27. Joint United Nations Programme on HIV/AIDS (UNAIDS). Stigma and Discrimination Factsheet. <http://data.unaids.org/publications/FactSheets03/fs stigma discrimination_en.pdf>. Accessed June 2012.

28. Azjen, I. and M. Fishbein. 1980. Understanding and Predicting Social Behavior. Englewood Cliffs, NJ: Prentice Hall.

29. Joint United Nations Programme on HIV/AIDS (UNAIDS). 2010. "We can empower young people to protect themselves from HIV." Joint action for results, UNAIDS outcome framework: Business case 2009-2011." Geneva: UNAIDS. 


\section{Study Team}

\section{Principal Investigator}

Babatunde Ahonsi

\section{Research Support Team}

Population Council Staff

Ayo Oginni

Otibho Obianwu

George Eluwa

Sylvia Adebajo

Segun Sangowawa

Lolade Abiodun

Segun Odumosu

Elizabeth Shoyemi

Francis Ukwuije

External Support

Oka Obono

Oliver Anene

Martin Mandanga

Nathan Nachandiya

Temitiope Akinwamide

Mezino Okoro

Onu Joy

Mayowa Ogunyale

Andrew Ogwuche

Charles Nwaigwe

Yinka Adebowale

Prince Joel

Zik Ahmed

Hauwa Ibrahim 
Population Council 16 Mafemi Crescent Abuja, Nigeria popcouncil.org 